\title{
A BRIEF REVIEW OF SOIL WATER, SOLUTE TRANSPORT AND REGIONALIZED VARIABLE ANALYSIS
}

\author{
D.R NIELSEN ${ }^{1}$; J.W. HOPMANS ${ }^{1}$; M. KUTILEK ${ }^{2}$; O. WENDROTH ${ }^{3}$ \\ ${ }^{1}$ Professor, Department of Land, Air and Water Resources, University of Califormia, Davis, Califormia 95616. \\ ${ }_{2}$ Professor, Faculty of Civil Engineering, Technical University Prague, Thakurova 7, 16629 Prague 6-Dejvice, Czech \\ Republic. \\ ${ }^{3}$ Research Soil Physicist, Center of Agrolandscape and Land Use Research, Institute for Soil Research, Ebersualder \\ Strasse 84, 15374 Muncheberg, Germany.
}

\begin{abstract}
We initinlly review basic concepts of the forces acting on soll water, soll water potential and soll water retention, and equations to describe soll water movement under water-saturated and unsaturated conditions. Processes of infiltration, evaporation and redistribution of water will be presented for simple inithal and boundary conditions occurring within homogeneous soll columns. Next we consiler the physical, chemical and biological processes within a soll profile that distribute, dilute or concentrate solute species within the liquid phase of a soll. The relative concentration of solutes in the liquid phase governs not only the retention and transport of water within solls but also contributes to our understanding of managing the quallity of water within solls and that moving below the recall of plant roots deeper into the vadose zone. A complete set of references about this subject is available in Kutb1ek \& Nielsen (1994), In the last section we recall the differences between classical statistical concepts and those that utilize the coordinates of space and time at which state variables across the landscape are observed. Our presentation will cover the hasic ideas about autocorrelation, crosacorrelation, applied time series analyses, atate space analyses and stmilar techniques currently belng used to enhance field research and investigations of land and water management.
\end{abstract}

Key Words: Solute transport, regionallned variable

\section{UMA BREVE REVISÃO DE ÁGUA NO SOLO, TRANSPORTE DE SOLUTO E ANÁLISE DE VARIÁVEL REGIONALIZADA}

RESUMO: Inicialmente foram reviados os conceitos bisicos das forgas que atuam sobre a hgua no solo, potencial e

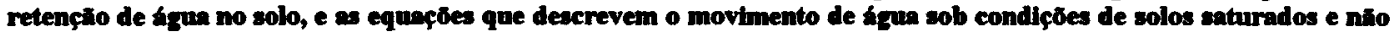
saturados. Os processos de infiltracilo, evaporaçio e redistribuiçio de igua foram apresentados para condiçes iniclal e de contorno que ocorrem dentro de colunas de solo homogêneo. Posteriormente, foram considerados os processos fisicos, químicos e blológicos dentro de um perfil do solo que distribuem, diluem ou concentram espécies de solutos na fase líquilda do solo. A concentraço relativa de solutos na fase liquida nî́o governa somente a retençio e o transporte da digua no solo, mas tambem contribui para a nossa compreensso para o manejo da qualidade da agua no solo e daquela que se move abairo das zonas radiculares. Um conjunto completo de referência concernente a esse assunto estí disponivel em Kutilek \& Nielsen (1994). No final do presente trabalho, formm recodadas as díferenças entre os conceitos da estatistica clássica e aqueles que utilizam as coordenadas de espaco e de tempo nas quais as variabilidades de espaco foram observadas ao longo da paisagem. A apresentacho cobre as ideias bassicas sobre antocorrelaçio, crosscorrelaclio, andilise de série temporal aplicada, ansilise de state-space e tecnicas atualmente utilizadas para subsidiar a pesquisa de campo, investigaçues sobre o solo e manejo de água.

Descritores: Tranaporte de solutos, varifivel regionalizada

\section{BASIC SOIL WATER CONCEPTS}

Forces acting on soil water: Here we study the system of soil and water in an equilibrium state, characterized by zero fluxes in the soil. The soil water content does not change in time and the water and its solutes are in equilibrium with internal and external forces acting on the system. Although we do not pay attention to the rate at which the equilibrium state was reached, we should know how the equilibrium was obtained. It is usually important to know the recent "history" of the system, e.g. was the equilibrium reached by wetting or drying of the soil? The forces may be grouped according to their nature into separate categories - adsorption, capillarity and swelling.

Adsorption: All three phases - solid, liquid and gas - usually occur simultaneously in most all soils. is the most frequent. Force fields existing at 
the interfaces of solid-liquid, liquid-gas and solidgas influence the behavior of soil water. Solutes in the soil water contribute to and modify the action of these force fields. The action between the surface of a solid soil particle including its sorbed ions and water takes place in close proximity of the surface. This portion of soil water is commonly called adsorption water. It can be most easily studied in the absence of other forces and is usually observed when limited amounts of water vapor are adsorbed on the solid soil particles. The adsorptive force field decreases with the distance from the solid surface. In Figure 1, the adsorbed water can be visualized as thin films covering the soil particle surfaces while capillary water to be discussed next occupies the wedges between the particles.

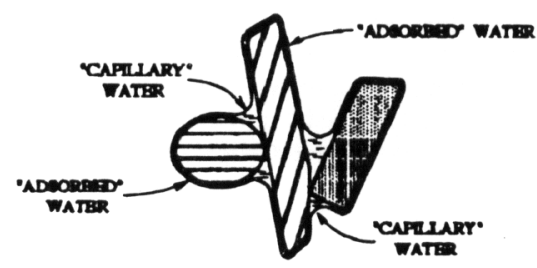

Figure 1 - Schematic diagram of adsorbed water and capillary water within soil pores.

Capillarity: Water filling only parts of the smaller spaces in an unsaturated soil forms curved interfaces between air and water. Capillary forces arise from these interfaces. When water meets a solid surface, a contact angle $\gamma$ is formed, see Figure 2. This contact angle is observed when a drop of water is placed on a plane solid surface, or when the solid plate is submerged into water. The magnitude of $\gamma$ is used to distinguish three classes of wetting for the solid surface. For $y=0^{\circ}$, the surface is completely wet and the solid is fully hydrophilic. A noncomplete wetting of the surface occurs for $O<y<$ $90^{\circ}$ and the solid is partly hydrophilic. A nonwetting surface exhibits y $290^{\circ}$ and the solid is hydrophobic.
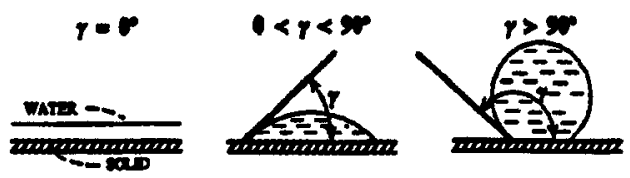

Figure 2 - Manifestation of the contact angle $y$ for a liquid on a solid.
Let us assume that the walls of a capillary of radius $\mathbf{r}$ are hydrophilic. Water rises into the capillary when its lower end is placed into a pool of water. The height $h$ of this capillary rise is

$$
|\mathrm{h}|=\frac{2 \sigma \cos \gamma}{\mathrm{r} \rho_{w} \mathrm{~g}}
$$

where $\sigma$ and $\rho$ are the surface tension and density of water, respectively, and $g$ the gravitational acceleration at the earth's surface. For water at $20^{\circ} \mathrm{C}$ and with $\gamma=0^{\circ},|\mathrm{h}|$ is approximately equal to $0.15 / \mathrm{r}$ for length units in $\mathrm{cm}$. Note in Figure 3 the magnitude of $h$ for the concave meniscus is less than zero. If we installed instruments for measuring the hydrostatic pressure, a straight line passing through zero at the plane water level would be observed. Below the water level, the hydrostatic pressure is positive, and above it in the water column of the capillary, the pressure is negative. The atmospheric pressure is taken as the reference.
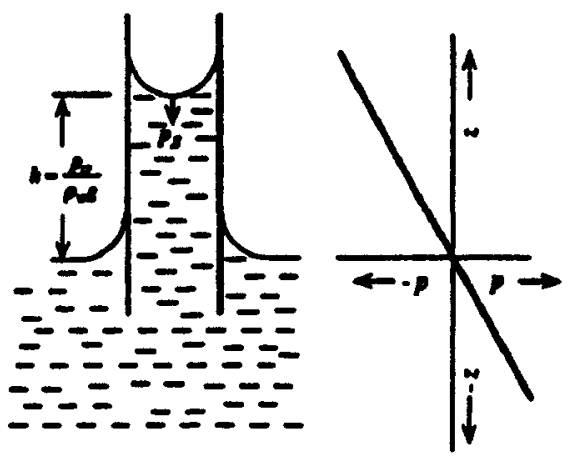

Figure 3 - Capillary rise for $0^{\circ}<\gamma<90^{\circ}$.

Similarly, when the capillarity of a water lens between spherical particles is studied (Figure 4), the convex-concave air-water interface yields a value of pressure $p$ defined by

$$
|p|=\sigma \cos \gamma\left(\frac{1}{R_{1}}+\frac{1}{R_{2}}\right)
$$

where $R_{1}$ is positive and $R_{2}$ is negative. From this discussion it follows that the soil water pressure is negative above the free (ground) water level. 


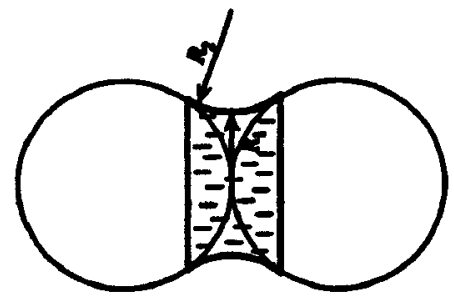

Figure 4 - A convex-concave air-water interface at the contact of two spherical particles. The water lens has two radii of curvature $\mathbf{R}_{\mathbf{1}}$ and $\mathbf{R}_{\mathbf{2}}$.

Swelling.: When water penetrates between two parallel clay particle surfaces, the surfaces tend to shift apart - a phenomenon called swelling. Swelling depends upon the clay content, mineralogical composition of clay and upon the exchangeable cations. Monovalent exchangeable cations induce greater swelling than divalent cations. When the clay fraction is dominated by montmorillonite, soils swell more than those dominated by chlorite or illite. The swelling of kaolinitic soils is negligible. An explanation of swelling starts with simple model of two parallel plates, which can demonstrate the behavior of plates of clay. Iwata et al. (1988) describe in detail the repulsive and attractive forces acting upon two parallel plates. In the foregoing presentation, although we shall neglect swelling and shrinkage, it must be remembered that such processes are important to the behavior of water and solute movement in field soils.

Soil Water Potential: The sum of the action of the above forces are all included within the concept of the soil water potential. Generally, the difference of the potential at two separate points relates to the driving force of the flow of soil water similar to the difference of temperature at the distant ends of a metallic rod that produces heat flow. Soil water potential is the pivotal concept of soil hydrology which treats the theory of soil water flow and retention. The potential energy of soil water is quantified relative to a reference state. The reference state is defined as the potential energy of pure water (with no external forces acting on it) at a reference pressure (which here we assume is the atmospheric pressure), a reference temperature and a reference elevation. Soil water potential is then the potential energy per unit quantity of water relative to the reference potential of zero.

The total potential is the summation of the component potentials

$$
\phi=\phi_{\mathrm{g}}+\phi_{\mathrm{w}}+\phi_{\mathrm{o}}+\phi_{\mathrm{a}}+\phi_{\mathrm{e}}
$$

where $\phi_{g}$ is the gravitational potential, $\phi_{w}$ the soil water potential, $\phi_{0}$ the osmotic potential, $\phi_{\mathrm{a}}$ the pneumatic potential and $\phi_{e}$ envelope potential.

Gravitational Potential: The gravitational force of attraction between any two bodies of mass $\mathrm{m}$ and $M$ is

$$
F=G \frac{M m}{r^{2}}
$$

where $r$ is the distance between the centers of the bodies and $\mathrm{G}$ is the universal gravitational constant equal to $6.6710^{-8} \mathrm{dyne} . \mathrm{cm}^{2} \cdot \mathrm{g}^{-1}$. If we assume that $M$ is the mass of the Earth and $m$ is that of water, the gravitational potential $\phi_{g}$ is defined by

$$
\phi_{g}=G M \int_{R}^{R-z} r^{-2} d r
$$

where $R$ is the radius of the Earth $\left(6.4 \cdot 10^{8} \mathrm{~cm}\right)$ and $\mathrm{z}$ is the vertical coordinate in the soil (in the order of $10^{2} \mathrm{~cm}$ ). Integrating (Equation 4), we have

$$
\phi_{g}=G M \int_{R}^{R-z} r^{-2} d r
$$

considering that $R \gg z$. Note from Equation 4 that $\mathrm{Fm}^{-1}=\mathrm{GMR}^{-2}$ which is $\mathrm{g}$, the gravitational acceleration of $980 \mathrm{~cm}^{-2} \mathrm{sec}^{-2}$ when evaluated at the Earth's surface $(r=R)$. Hence, the gravitational potential increases linearly with elevation according to

$$
\phi_{\mathrm{g}}=\mathrm{gz}
$$

Soil Water Potential: Soil water potential is defined as the amount of work per unit quantity of pure water that must be done by external forces to transfer reversibly and isothermally an infintesi- 
mal amount of water from the standard state to the soil point under consideration. The use of the definition is illustrated in Figure 5 where the soil water retention curve is constructed.

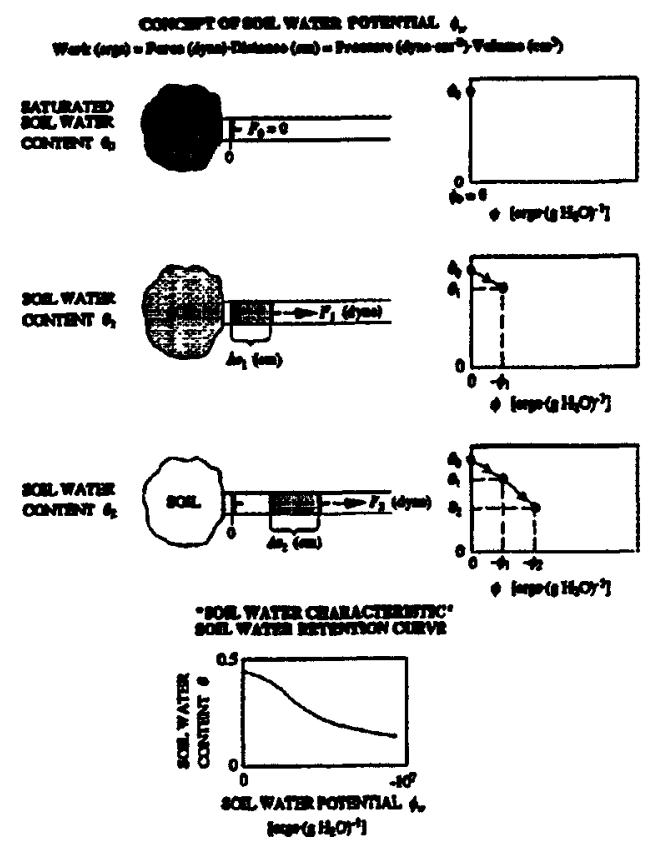

Figure 5 - Illustration of soil water potential.

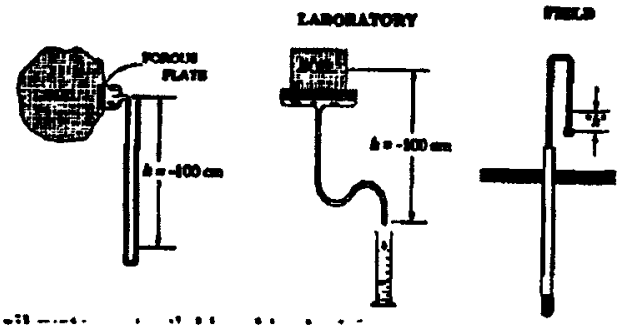

Figure 6 - Measurement of the soil water potential head in the laboratory and the field.

The soil water retention curve or the "soil water characteristic" relates the volumetric soil water content to the soil water potential. Notice that the individual forces associated with adsorption, capillarity, adhesion, cohesion etc. are not individually or collectively measured. Rather, the potential energy associated with their combined effects is estimated over a small soil volume. From the concept given in Figure 5, we see in Figure 6 how soil water potential is measured in the laboratory and the field.

Osmotic Potential: Osmotic potential $\left(\phi_{0}\right.$ is owing to the difference in the chemical composition of the soil solution related to free, pure, bulk water at the same elevation. Richards (1965) explained the meaning of the osmotic potential with a set of pools, and a manometer or tensiometer attached to each of the pools as illustrated in Figure 7.

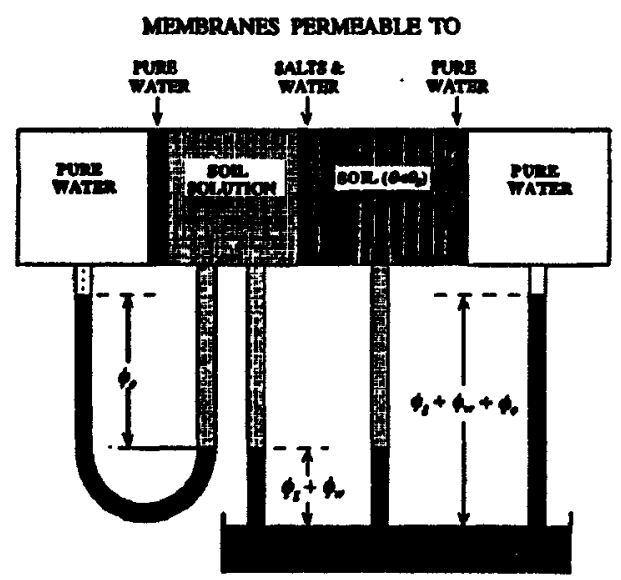

Figure 7 - Demonstration of gravitational $\phi_{\mathrm{g}}$, osmotic $\phi_{0}$ and soil water $\phi_{w}$ potential heads after Richards (1965).

The pools are separated by semipermeable membranes permeable only to specified substances. The central pool contains an unsaturated soil with water actually being a solution. The soil is separated by a membrane permeable only to water from the pool on the right containing pure water and by a membrane permeable only to soil solution from the pool on the left containing soil solution. This latter pool containing the solution of the same concentration as the soil water is separated by a membrane permeable only to water from the next pool to its left containing pure water. The differential manometer on the left shows a pressure height identical to the osmotic potential $\left(\phi_{0}\right.$, while the manometer attached to the pool with the soil solution shows the sum of the gravitational and 
the soil water potential $\left(\phi_{B}+\phi_{W}\right)$. The same value of $\left(\phi_{g}+\phi_{w}\right)$ is read if a tensiometer is inserted into the soil inasmuch as its porous cup is permeable to both water and its dissolved substances. The manometer attached to the pool with pure water shows the sum of the potentials $\left(\phi_{g}+\phi_{w}+\phi_{0}\right)$.

Pneumatic Potential: The pneumatic potential $\phi_{\text {e }}$ accounts for air pressure inside the soil pores being different from the atmospheric air pressure acting upon the reference water.

Envelope Potential: When an external mechanical pressure such as the overburden pressure of the topsoil layers acts upon the soil, the magnitude of change of the total potential is expressed by the envelope potential $\phi_{e}$. The contribution of $\phi_{e}$ is usually negligible for sandy soils and becomes more important for soils having greater clay contents. In sands, because the external pressure is transmitted almost completely by the direct contacts of the grains, especially in pre consolidated sands, the potential of the pore water is not altered by the external pressure. When the external pressure is transmitted from particle to particle via the water film envelopes around the particles, the pore water is greatly influenced and the value of $\phi_{e}$ is significant.

We note here that the potential measured with a tensiometer is $\left(\phi_{w}+\phi_{t}+\phi_{e}\right)$ provided that the solution within the tensiometer cup is at chemical equilibrium with that in the soil. The provision is not fully met in saline soils or even in non saline soils whenever the concentration of the soil solution changes abruptly in the vicinity of the tensiometer cup.

In the majority of situations the simplest definition of the total potential is

$$
\phi=\phi_{w}+\phi_{g}
$$

and with the potential expressed as energy per unit weight of water

$$
\phi=\operatorname{gh}(x, y, z, t)+z
$$

the total head $H$ is simply

$$
H=h(x, y, z, t)+z
$$

where $x$ and $y$ are horizontal coordinates, $z$ the vertical distance from the reference level, positive upwards and $t$ time. For soils not fully saturated with water, $h<0$.

When Does Water Not Move? According to Newton's laws, a body is at rest or moving at a constant velocity when the sum of forces acting on it is zero. Because we do not measure the forces acting on soil water, we must calculate the total force. What must be the condition to have no flow in the horizontal directions? There should be no force acting on the water in the horizontal directions. Hence, the partial dervatives of Equation 9 with respect to both $x$ and $y$ must each be identically zero. In other words,

$$
\begin{gathered}
F=-\frac{\partial \phi}{\partial x}=-g \frac{\partial \mathrm{h}}{\partial \mathrm{x}}=0 \\
F=-\frac{\partial \phi}{\partial y}=-\mathrm{g} \frac{\partial \mathrm{h}}{\partial \mathrm{y}}=0
\end{gathered}
$$

In as much as B is not zero, the values of $h$ must be constant in both directions.

What must be the condition to have no flow in the vertical direction? There should be no force acting on the water in the vertical direction. Hence, the partial dervative of Equation 9 with respect to $\mathrm{z}$ must be identically zero.

$$
F=-\frac{\partial \phi}{\partial z}=-g \frac{\partial h}{\partial z}-g \frac{\partial z}{\partial z}=-g\left(\frac{\partial h}{\partial z}+1\right)=0
$$

Because the parenthetic value must be nil,

$$
\mathbf{h}=-\mathbf{z}+\mathbf{c}
$$

where $c$ is a constant of integration. When no water flows vertically, the values of $h$ and $z$ throughout the soil must equal but opposite in sign.

Two examples are illustrated in Figure 8 when water tables exist at a soil depth of 100 $\mathrm{cm}$ and at the soil surface. Note that under the wetter condition with the water table at the soil surface the magnitude of the total potential $\sim$ is greater, but its derivative remains nil.

Rate of Soll Water Flow: The rate at which water moves through a soil is proportional to the force acting on the water, 


$$
\bar{q} \alpha \bar{\nabla} \phi
$$

where $\bar{q}$ is the flux density vector equal to the volume of water moving per unit time through a unit surface area normal to the direction of flow. If we consider the flux density in only the vertical direction, Equation 13 becomes

$$
q \alpha-\frac{d \phi}{d z}=-g \frac{d\left(\phi_{w} \cdot g^{-1}+\phi_{g} \cdot g^{-1}\right)}{d z}
$$

or

$$
q \alpha-g \frac{d(h+z)}{d z}=-g\left(\frac{d h}{d z}+1\right)
$$
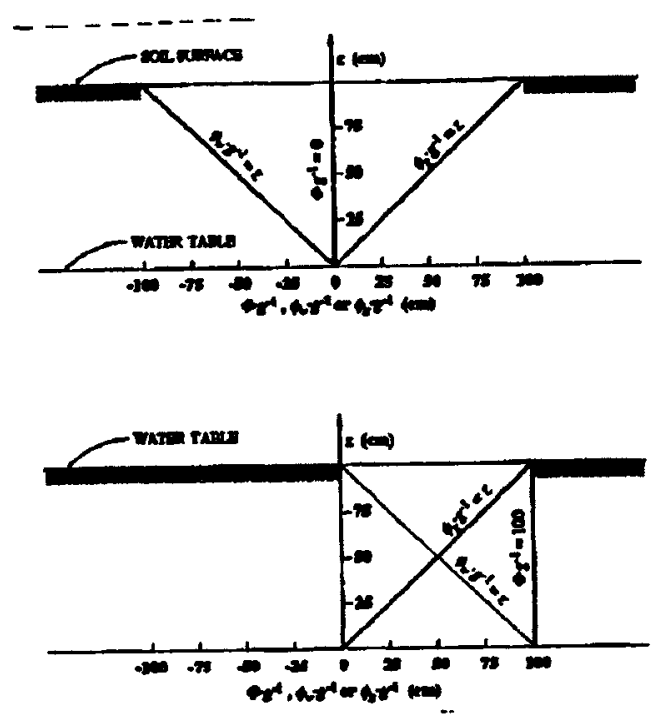

Figure 8 - Vertical potential distributions for two stagnant flow conditions.

If we assume the flux density $q$ and the force given by the last term in Equation 15 are related equal by a constant for a particular value of $h$ or 9 , we have the Darcy-Buckingham equation

$$
q=-K\left(\frac{d h}{d z}+1\right)
$$

where the hydraulic conductivity $\mathrm{K}(\mathrm{h})$ equals $k \rho \gamma \mu^{-1}$ with $k$ being the intrinsic permeability reflecting the geometry of the soil pores, and $p$ and the density and viscosity of the soil water, respectively.

A simple example of unsaturated flow is demonstrated in Figure 9. The cylinder containing the soil has small openings within its walls leading to the atmosphere. Semipermeable membranes, permeable to water but not to air, separate the soil from free water on both sides of the cylinder. The pools of water are connected to the cylinder with flexible tubes. Full saturation of the soil is first achieved when both pools, lifted to the highest point of the soil, displace the soil air through the openings on the top side of the cylinder. At this moment, there is no flow in the system and the soil is assumed water saturated. With the pool on the left side of the cylinder lowered to the position $h \sim$ and the pool on the right side to position h2, air enters into the soil through the openings as the soil starts to drain in

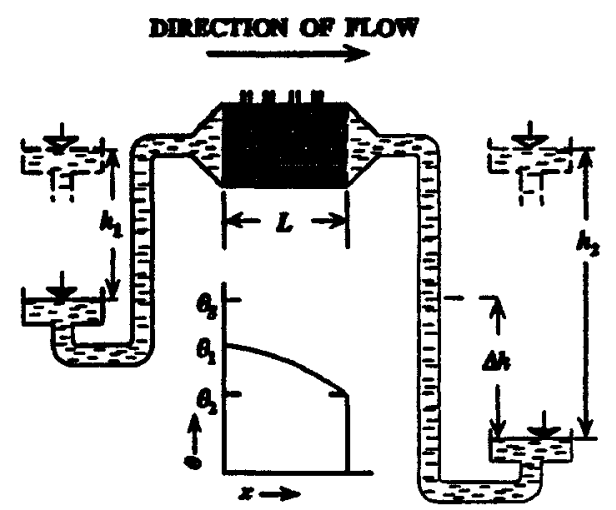

Figure 9 - A simple steady flow experiment on an unsaturated soil column.

a manner similar to a soil placed on a tension plate apparatus. Although water flows from the left pool to the right pool, the rate of flow is reduced significantly compared with that when the soil is water saturated. If the water level in each of the pools is kept at a constant elevation with time, steady flow will eventually be reached with the water content at each point within the soil remaining invariant. At this time, the flux density $q$ will depend upon the hydraulic gradient and be governed by an equation similar to Equation 16 with the force of gravity omitted 
because water is flowing only horizontally with the gravitational head being every where the same

$$
q=-K\left(\frac{d h}{d z}+1\right)
$$

Inasmuch as the soil is not water saturated and flow occurs primarily in those pores filled with water, the value of $K$ will be smaller than that of the saturated hydraulic conductivity Ks for the same soil. The unsaturated hydraulic conductivity $\mathrm{K}[\mathrm{h}(\theta)]$ is physically dependent upon the soil water content $\theta$ because water flow is realized primarily in pores completely filled with water. Coarse-textured soils generally have greater values of $K$ than those of fine-textured soils near water saturation $(-h \rightarrow 0)$. On the other hand, fine-textured soils usually have the greater values as the value of $h$ diminishes. See Figure 10.

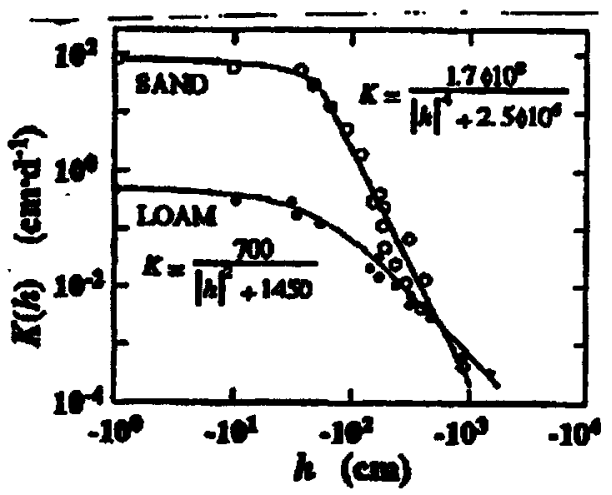

Figure 10 - Measured values of $\mathrm{K}(\mathrm{h})$ for a sand and a loam (Willis, 1960).

The experimental values of $K$ satisfy the empirical relation

$$
K=\frac{a}{|h|^{n}+b}
$$

where $\mathbf{a}, \mathbf{b}$ and $\mathbf{n}$ are constants. Values of $\mathbf{n}$ for clays are about 2 while those for sands are 4 or greater. Note that when h 20 in Equation 18 the ratio of $a$ and $b$ is the value of the saturated hydraulic conductivity $\mathrm{Ks}$.

Direction of Soll Water Flow: The direction of vertical flow depends upon the magnitude and sign of the derivative of $h$ compared to 1 in Equation 16. For $q>0$, water flows upward and for $q<0$, water flows downward. See Figure 11 .

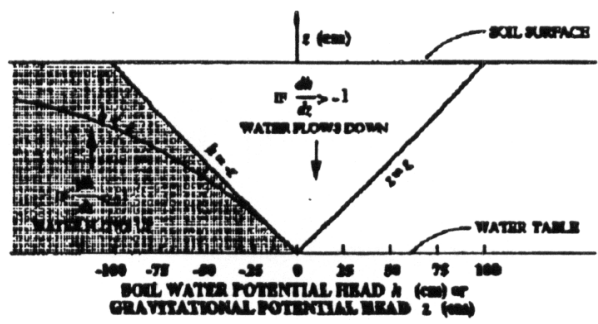

Figure 11 - Soil water potential head distributions for vertical upward and downward water flow.

Rate and Direction of Soll Water Flow: When the Darcy-Buckingham law contains the functional form of $K(h)$ for a particular soil, and if the steady-state boundary conditions are specified, Equation 16 may be integrated to yield the magnitude and direction of water flow as well as the distribution in(z) within the soil profile. As an example, we choose a loam soil having values of $\mathrm{a}, \mathrm{b}$ and $\mathrm{n}$ in Equation 18 equal to $200 \mathrm{~cm}^{3} \mathrm{~h}^{-1}$, $100 \mathrm{~cm}^{2}$ and 2 , respectively. We specify that a water table exists at the $3 \mathrm{~m}$ depth. If we specify the flux density, we may calculate the distribution $h(z)$. To avoid complications of signs, we shall select $\tau=-h$ where $\tau$ is always positive in our calculations. Hence, we designate the total potential head $\mathrm{H}=(\tau+\mathrm{z})$ with the reference level for gravitational potential being zero at the water table $\mathrm{z}=0$.

Substituting Equation 18 into Equation 16 and integrating with respect to the above boundary conditions, we have

$$
\int_{0}^{100} d z=\int_{0}^{1} \frac{d \tau}{1+q \cdot k^{-1}(\tau)}=\frac{a}{q} \int_{0}^{2}\left[a \cdot q^{-1}+b+\tau^{2}\right]^{-1} d \tau
$$

Note that if $q$ is known, the equation can be solved for its only unknown quantity $\sim$ at the soil surface. On the other hand if $\sim$ is specified, the value of $q$ can be calculated.

Depending on the sign of $q$, and the relative magnitudes of $a$ and $b$, the integral in Equation 19 is of the form

$$
\int \frac{d u}{c^{2}-u^{2}}=\frac{1}{2 c} \ln \left(\frac{c+u}{c-u}\right) \text { or }
$$




$$
\int \frac{d u}{c^{2}+u^{2}}=\frac{1}{c} \tan ^{-1}\left(\frac{u}{c}\right)
$$

For infiltration with $q<0$, the first form is appropriate and becomes

$$
\int_{0}^{300} d z=a \cdot|q|^{-1} \int_{0}^{\tau}\left\{\left[\left(a \cdot|q|^{-1}-b\right)^{1 / 2}\right]^{2}-\tau^{2}\right\}^{-1} d \tau(21)
$$

Upon integration, Equation 21 becomes

$$
300=\frac{a}{2|q|\left(a \cdot|q|^{-1}-b\right)^{1 / 2}} \ln \left[\frac{\left(a \cdot|q|^{-1}-b\right)^{1 / 2}+\tau}{\left(a \cdot|q|^{-1}-b\right)^{1 / 2}-\tau}\right]
$$

For steady infiltration rates $q$ equal to $0.001,-0.01,-0.1$ and $-1 \mathrm{~cm}^{-1}$, the values of $\mathrm{h}$ at the soil surface are $-355,-262,-137,-43.6$ and $9.99 \mathrm{~cm}$, respectively. The corresponding distributions of $\mathrm{z}(\mathrm{h})$ given by Equation 22 are illustrated in Figure 12.

For evaporation with $q>0$, the second form Equation 20 becomes

$$
\int_{0}^{300} d z=a \cdot q^{-1} \int_{0}^{\tau}\left\{\left[\left(a \cdot q^{-1}-b\right)^{1 / 2}\right]^{2}+\tau^{2}\right\}^{-1} d \tau(23)
$$

and upon integration is

$$
300=\frac{a}{q\left(a \cdot q^{-1}+b\right)^{1 / 2}} \tan ^{-1}\left[\frac{\tau}{\left(a \cdot q^{-1}+b\right)^{1 / 2}}\right](24)
$$

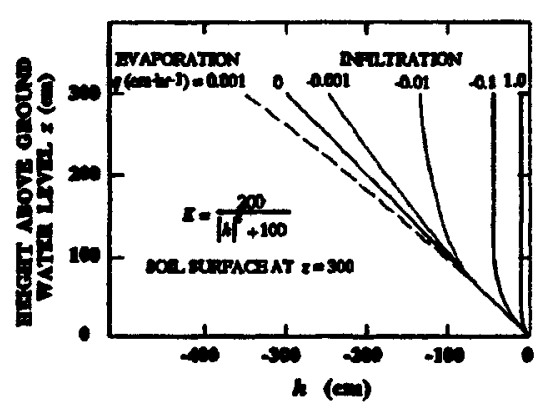

Figure 12 - Soil water potential head distributions for steady state evaporation, no flow and infiltration.
The distribution by Equation 24 is given in Figure 12 for an evaporation rate $q=0.001$ $\mathrm{cm} \mathrm{h}^{-1}$. At that rate, the value of $h$ at the soil surface is $-355 \mathrm{~cm}$. We note that a maximum evaporation rate of $0.00547 \mathrm{~cm} \mathrm{~h}^{-1}$ is reached by allowing the value of $h$ at the soil surface to decrease and approach - $\infty$. Integrating Equation 19 for other soils ( $n=3,4,5$ etc.) for soils that are progressively more sandy, it can be easily shown that the maximum rate of evaporation is proportional to $L-n$ where $L$ is the depth of the water table.

Steady Infiltration into a 2 - Layered Soil: The simplest case is the crust-topped profile. Rainfall frequently destroys soil aggregates within a soil surface. Tillage also induces compaction. Both processes processes often denoted by sealing, crusting or compaction results in the formation of a less permeable soil surface layer. The characteristics of the topsoil will be denoted by the index 2, while those of the subsoil will be given the index 1, see Figure 13.

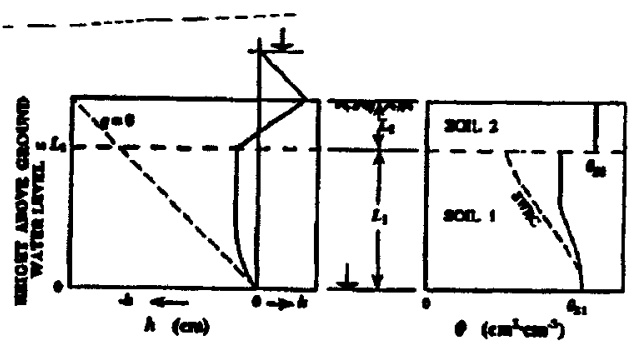

Figure 13 - Steady flow infiltration into a twolayered soil.

The origin of the z-axis is identical with the position of the ground water level which is kept constant. The thickness of the subsoil between the ground water level and the topsoil is $L_{1}$, the thickness of the topsoil $L_{2}$ and the depth of water on the soil surface ho. For steady-state flow, $q_{1}=q_{2}$, and we have

$$
300=\frac{a}{q\left(a \cdot q^{-1}+b\right)^{1 / 2}} \tan ^{-1}\left[\frac{\tau}{\left(a \cdot q^{-1}+b\right)^{1 / 2}}\right]
$$

If $K_{S 1} \gg K_{S 2}$, and $K_{1}\left(h_{I}\right) \gg K_{2}\left(h_{1}\right)$ where $h_{1}$ is the value of $h$ at the interface, we have 


$$
\left(\frac{\mathrm{dH}}{\mathrm{dz}}\right)_{1} \ll\left(\frac{\mathrm{dH}}{\mathrm{dz}}\right)_{2}
$$

and because $\mathrm{H}=(\mathrm{h}+\mathrm{z})$

$$
\left(\frac{d h}{d z}\right)_{1} \ll\left(\frac{d h}{d z}\right)_{2}
$$

This condition of a larger gradient of $h$ occurring in the topsoil (layer 2) demands a sufficiently small value of $h /$ including $h_{h}<0$. Because we assume that just below the interface in the subsoil (layer 1), $\mathrm{dH} / \mathrm{dz} \approx 1$, we can write

$$
q=-K_{1}\left(h_{1}\right)
$$

For the topsoil assuming it remains water-saturated,

$$
q=-K_{s 2}\left(\frac{h_{0}+h_{1}+L_{2}}{L_{2}}\right)
$$

The value of $h_{1}$ is obtained by equating Equation 28 and Equation 29. The subsoil can be unsaturated if $|\mathfrak{q}|<K_{\mathbf{s i}}$. Under the assumptions here, the subsoil becomes unsaturated below the topsoil when

$$
h_{0}<L_{2}\left(\frac{K_{\text {S1 }}}{K_{s 2}}-1\right)
$$

For more general conditions than those assumed here, the bottom of the topsoil above the interface can also become unsaturated. For such cases, the above approach has to be modified, see e.g. Takagi (1960) and Srinilta et al. (1966).

Unsteady Infiltration into a Soil: Let us assume that the soil is initially at some uniform water content $q_{n}$. Water can enter the soil surface as a result of rainfall or some sort of irrigation technique. The soil water potential or water flux density existing at the soil surface dominates the infiltration process. If the soil surface is suddenly and continuously flooded with a negligibly small depth of water $(h=0)$, the soil near or at the surface can be assumed water saturated. It is also possible to maintain a constant soil water potential head $h<0$, which $\theta$ is maintained constant and less than $\theta_{s}$. Such a boundary condition is known as Dirichlet's boundary condition. For such a condition, the water flux density at the soil surface changes as infiltration occurs. On the other hand, if the flux density at the soil surface is assumed known, Neuman's boundary condition exists. It can describe constant rainfall at rates less than as well as greater than $\mathrm{K}_{\text {\&, }}$ and nonconstant rainfall. It also is appropriate for controlled sprinkler and other flux controlled techniques for applying water to the soil surface. Here we give a couple of examples using only the Dirichlet condition.

The primary infiltration data usually measured are values of cumulative infiltration I (cm) as a function of time. The values represent the total amount of water infiltrated into the soil from the beginning of the infiltration test at $t=0$. A typical $l(t)$ relationship (Figure 14 ) is a smooth, monotonically rising curve.

The infiltration rate $\mathrm{q}_{0}=\mathrm{d} / \mathrm{dt}$ where the subscript o refers to the soil surface at $z=0$. The value of $q_{0}$ initially decreases rapidly with time and eventually approaches a constant value. For $\mathrm{t}=0, \mathrm{q}_{0} \rightarrow \infty$, and for $\mathrm{t} \rightarrow \infty, \mathrm{q}_{0}=$ constant. Theoretically, $q_{0} \rightarrow K_{s}$ as $t \rightarrow \infty$. Practically, the infiltration rate starts to be constant for coarse textured soils after only decades of minutes while

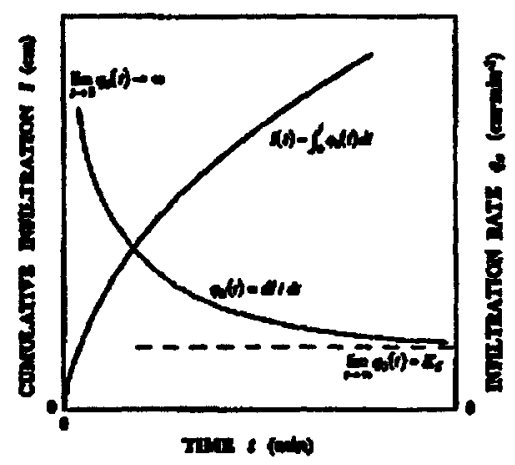

Figure 14 - Time dependence of cumulative infiltration and infiltration rate.

When unsteady soil water flow exists, two equations are needed to describe the water flux density and the rate of change of soil water content in time. The flux density described by the 
Buckingham-Darcy equation and the rate of filling or emptying of the soil pores described by the equation of continuity are combined into the Richards' equation

$$
\frac{\partial \theta}{\partial \mathrm{t}}=\frac{\partial}{\partial \mathrm{z}}\left[\mathrm{D}(\mathrm{h}) \frac{\partial \mathrm{h}}{\partial \mathrm{z}}\right]-\frac{\partial \mathrm{K}}{\partial \mathrm{z}}
$$

for vertical, one-dimensional flow where $z$ is measured positively in the downward direction.

If the soil is only wetting, $\theta$ will be uniquely dependent upon only $h$ and

$$
\frac{\partial \mathrm{h}}{\partial \mathrm{z}}=\frac{\mathrm{dh}}{\mathrm{d} \theta} \frac{\partial \theta}{\partial \mathrm{z}}
$$

which leads to the diffusivity form of Richards' equation

$$
\frac{\partial \theta}{\partial \mathrm{t}}=\frac{\partial}{\partial \mathrm{z}}\left[\mathrm{D}(\theta) \frac{\partial \theta}{\partial \mathrm{z}}\right]-\frac{\partial \mathrm{K}}{\partial \mathrm{z}}
$$

where the Darcy-Buchingham equation has the diffusivity form

$$
q=-D(\theta) \frac{\partial \theta}{\partial z}-K(\theta)
$$

and the soil water diffusivity $D$ is the term derived from

$$
D(\theta)=K(\theta) \frac{d h}{d \theta}
$$

The main reason for the derivation of Equation 33 is the reduction of the number of variables from 4 to 3 .

The first term on the right hand side of Equation 33 accounts for the forces associated with differences of the soil water potential as illustrated in Figure 5. The second term on the right hand side of Equation 33 accounts for the gravitational force because water is moving vertically. During early stages of infiltration the second term is negligible, and during late stages it dominates the process. Hence, here we shall first neglect it and assume water flows horizontally not influenced by gravity, and later consider its influence.
Our horizontal soil column, initially at an unsaturated water content $\theta_{n}$, has its end at $x=$ 0 maintained at water saturation $\theta_{\mathrm{s}}$. Hence, for

$$
\begin{array}{lll}
t \geq 0 & x=0 & \theta=\theta_{s} \\
t=0 & x>0 & \theta=\theta_{n}
\end{array}
$$

we solve Equation 33 without the gravitational term

$$
\frac{\partial \theta}{\partial \mathrm{t}}=\frac{\partial}{\partial \mathrm{x}}\left[\mathrm{D}(\theta) \frac{\partial \theta}{\partial \mathrm{x}}\right]
$$

It is only here for a homogeneous soil (i.e. not layered) that the gradient of $\theta$ represents the driving force of the process. Here when $D$ is a function of $\theta$, we must transform Equation 38 into an ordinary differential equation using the Boltzmann transformation.

The transformed equation has a new variable $\eta$ instead of the two original variables $x$ and $t$. The new variable $\eta$ defined by the Boltzmann transformation

$$
\eta(\theta)=\mathrm{xt}^{-1 / 2}
$$

transforms Equation 38 to

$$
-\frac{\eta}{2} \frac{d \theta}{d \eta}=\frac{\partial}{\partial \eta}\left[D(\theta) \frac{d \theta}{d \eta}\right]
$$

with transformed boundary conditions

$$
\begin{array}{ll}
\eta=0 & \theta=\theta_{s} \\
\eta=\infty & \theta=\theta_{n}
\end{array}
$$

The solution for which we search is simply $\theta(\eta)$, see Equation 39 and Figure 15 . Measured soil water profiles $\theta\left[x\left(t_{1}\right)\right], \theta\left[x\left(t_{2}\right)\right]$, $\theta\left[x\left(t_{3}\right)\right]$ etc. are thus transformed into the unique $\theta(\eta)$ relationship by merely dividing $x$ by $t_{1}{ }^{1 / 2}$ for the first profile, $t_{2}{ }^{1 / 2}$, for the second profile etc. Note that for $t=1, x \equiv \eta$. Hence, the physical reality of $\theta(\eta)$ is the soil water profile $\theta(x)$ when the infiltration time is unity. 


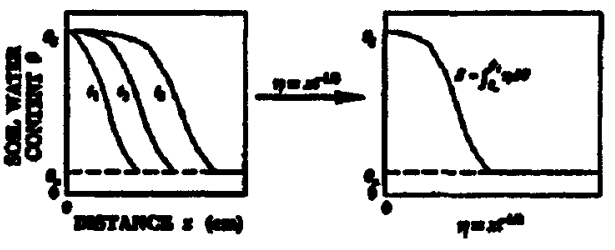

Figure 15 - Boltzmann's transformation reduces the soil water content profiles $\theta(x)$ into a unique profile $\theta(\eta)$ for horizontal infiltration.

The amount of water infiltrated into the profile is

$$
I=\int_{\theta_{1}}^{\theta_{3}} x d \theta
$$

or with Equation 39,

$$
I=\int_{\theta_{0}}^{\theta_{8}} \eta[\theta) t^{1 / 2} d \theta
$$

With the sorptivity $S$ being defined as

$$
S=\int_{\theta_{n}}^{\theta_{\mathrm{g}}} \eta[\theta] \mathrm{d} \theta
$$

we have the cumulative infiltration

$$
\mathbf{I}=\mathrm{St}^{1 / 2}
$$

Because the infiltration rate

$$
q_{0}=\frac{d I}{d t}
$$

we also have

$$
\mathrm{q}_{0}=\frac{1}{2} \mathrm{St}^{-1 / 2}
$$

Here, we note that the sorptivity is physically the cumulative amount of water infiltrated at $t=1$, and at that time, the infiltration rate has diminished to one-half the value of $S$. Sorptivity depends not only upon the $D(\theta)$ function but upon $\theta_{\mathrm{n}}$. The value of $S$ decreases with increasing $\theta_{i}$ and as $\theta_{1} \rightarrow \theta_{\mathrm{s}}, \mathrm{S}$ $\rightarrow \mathbf{0}$.

Sorptivity is an integral part of most investigations describing vertical infiltration as we shall learn below.

The solution of Equation 33 subject to Equation 38 and Equation 39 for vertical infiltration is

$$
z(\theta, t)=\eta(\theta) t^{1 / 2}+\chi(\theta) t+\Psi(\theta) t^{3 / 2}+\ldots+f_{i}(\theta) t^{i / 2}(49)
$$

The cumulative infiltration I is

$$
I=S t^{1 / 2}+\left(A_{2}+K_{a}\right) t+A_{3} t^{3 / 2}+\ldots+A_{1} t^{i / 2}(50)
$$

where $K_{n}$ is $K\left(\theta_{n}\right)$. Note that $K_{n} t$ expresses the cumulative water flow with $\mathrm{dH} / \mathrm{dz}=-1$ at $\theta=\theta_{\mathrm{n}}$. The series Equation 50 converges for short and intermediate times of infiltration and the infiltration rate $q_{\alpha}(t)$ obtained by differentiation is

$$
q_{0}=\frac{1}{2} s t^{-1 / 2}+\left(A_{2}+K_{1}\right)+\frac{3}{2} A_{3} t^{1 / 2}+\ldots+\frac{i}{2} A_{1} t^{1 / 2-1}(51)
$$

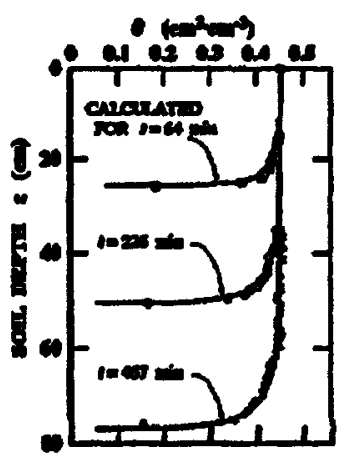

Figure 16 - Measured and calculated soil water content profiles in Columbia silt loam for a Dirichlet boundary condition.

For large times, Equation 50 does not converge. Inasmuch as the shape of the wetting front remains invariant at large times, the wetting front moves downward at a rate

$$
v=\frac{K_{s}-K_{n}}{\theta_{s}-\theta_{n}}
$$


while the infiltration rate for $t \rightarrow \infty$ is

$$
\mathrm{q}_{0}=\mathbf{K}_{\mathrm{s}}
$$

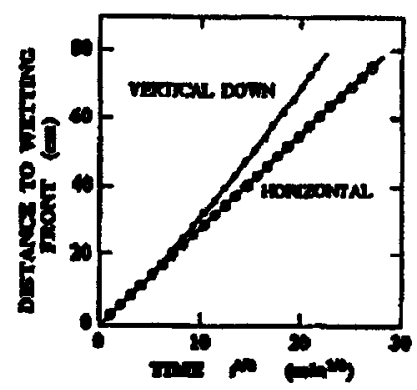

Figure 17 - Distance to the wetting front versus square root of time for vertical and horizontal infiltration into Columbia silt loam.

Soil water content profiles measured at three different infiltration times in the laboratory for a homogeneous column of Columbia silt loam are given in Figure 16. The solid lines are calculated using measured values of $\mathrm{K}(\sim)$ and $D(\sim)$ in the above equations. The extra depth to which the soil water profile advances owing to the force of the gravitational field is illustrated in Figure 17 where the distance to the wetting front for horizontal and vertically downward flows are plotted against the square root of time.

During the first $25 \mathrm{~min}$, the depths of wetting for both horizontal and vertical infiltration are nearly identical. After $400 \mathrm{~min}$, the vertical profile is more than $12 \mathrm{~cm}$ deeper than that of the horizontal profile, and the infiltration rate is nearly constant and equal to $\mathrm{K}_{\mathbf{S}}$ according to Equation 53.

Redistribution of Water after Infiltration: After infiltration ceases, the soil water content gradually decreases even when the soil surface is protected by a cover allowing no evaporation. The decrease of $\theta$ within the originally wetted topsoil is caused by a downward flow of soil water. When water draining from the wetted topsoil wets the originally drier subsoil, we speak of soil water redistribution. At that time a relatively large soil water potential frequently near $h=0$ exists within the topsoil down to the depth of the wetting front $Z_{r}$. Below the wetting front, the value of $h$ is very small, and hence, the soil water profile is in a dynamic state rather than one of equilibrium. When we discuss this non-equilibrium process caused by infiltration, we denote the time of cessation of infiltration to $=0$. The nonequilibrium produces a downward water flux within the soil profile without a contribution to the flux from the surface, i.e. at $z=0, \theta_{0}=0$. With the soil between $\mathrm{z}=0$ and $\mathrm{z}=\mathrm{Z}_{\mathrm{f}}$ being drained, water flows below $Z_{\mathrm{f}}$ forming a new redistribution wetting front at $\mathrm{Zr}$, see Figure 18a.

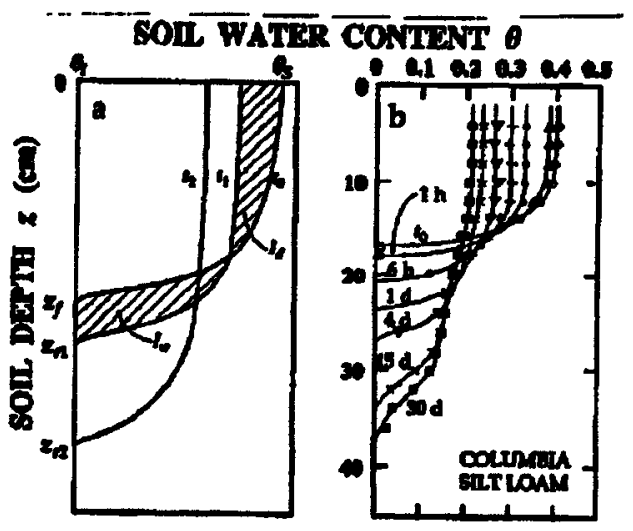

Figure 18 - Conceptual and measured soil water content profiles during redistribution after infiltration.

The soil water content profile $\theta(z)$ at $t_{0}$ is the profile at the end of infiltration. Subsequently, at times $t_{1}, t_{2}, t_{3}, \ldots$, redistribution profiles are observed. The cumulative drainage ld and the cumulative wetting Iw below $Z_{f}$ are equal for the time interval $\left(0, t_{1}\right)$, see the hatched areas in Figure 18a. The rate of movement depends upon the hydraulic conductivity and the depth of the original wetting front from the infiltration. The flux density across the redistribution front decreases in time owing to two factors. First, the potential in the wetted topsoil decreases with a simultaneous decrease of the gradient of the total potential $\mathrm{dH} / \mathrm{dz}$. Second, the value of the hydraulic conductivity decreases strongly with only slight decreases of $\theta$.

Soil water profiles during redistribution in Columbia silt loam given in Figure 18b resemble those in Figure 18a. At time to, $6.1 \mathrm{~cm}$ of water had just infiltrated the soil surface with the wetting front reaching $17 \mathrm{~cm}$. Soil water contents near the soil surface decrease gradually 
and uniformly by developing zones of nearly constant water content extending from the soil surface downward. After $30 \mathrm{~d}$ of redistribution, the wetting front has reached nearly $40 \mathrm{~cm}$ and the water content at the soil surface has diminished to $0.21 \mathrm{~cm}^{3} \mathrm{~cm}^{-3}$. At that time the initially abrupt wetting front into the dry soil is no longer evident, indicative of water movement at extremely small water contents. Other measurements of redistribution in columbia silt loam showed that rate of redistribution is inversely related to the initial depth of wetting which is just the opposite for sands.

Water Vapor Transport in Dry Soils: In relatively dry soils when a great portion of the pores are filled with air and liquid water exists in very thin layers on the soil particle surfaces, the flux density of water is composed primarily of vapor, not liquid water. For nonisothermal conditions, the transfer of water vapor is even greater. Jackson (1964) performed a simple experiment to demonstrate how water vapor moves through soils. Theoretically for an inert porous medium, he assumed that the steady state water vapor flux density qv4, was described by Fick's first law of diffusion

$$
q_{\text {vap }}=-D_{v} \frac{\partial \rho}{\partial x}
$$

where $D_{v}$ is the soil water vapor diffusivity and $p$ the water vapor density in the soil air. Combining Equation 54 with the equation of continuity

$$
\varepsilon \frac{\partial p}{\partial t}=\frac{\partial q_{v}}{\partial x}
$$

we have for transient conditions in an inert medium

$$
\varepsilon \frac{\partial \rho}{\partial t}=\frac{\partial}{\partial x}\left(D_{v} \frac{\partial \rho}{\partial x}\right)
$$

where $\varepsilon$ is the air-filled porosity. Because soil is not inert, it can absorb the water vapor and have it condense on its particles' surfaces as well as the reverse - contribute to the vapor density of its air filled pores from the liquid water on its particle surfaces. At equilibrium the adsorption isotherm $\rho(\theta)$ expresses the relation between the water in the soil air to that in the liquid state. Recognizing that $\rho$ is a function of the soil water content $\theta$, Equation 54 becomes

$$
q_{\mathrm{vap}}=-D_{v} \frac{d \rho}{d \theta} \frac{\partial \theta}{\partial x}=-D_{\theta_{v p}} \frac{\partial \theta}{\partial x}
$$

where $D_{\theta_{v p}}$ is the product of $D_{v}$ and the slope of the vapor adsorption isotherm $\rho(\theta)$. For a soil, Equation 56 becomes

$$
\varepsilon \frac{\partial \rho}{\partial t}=\frac{\partial}{\partial x}\left(D_{\theta_{v-}} \frac{\partial \theta}{\partial x}\right)-\frac{\partial \theta}{\partial t}
$$

where the second term on the right-hand side of Equation 58 accounts for the water vapor being adsorbed on the soil and changing the soil water content $\boldsymbol{\theta}$. If

$$
\varepsilon \frac{\partial \rho}{\partial t} \ll \frac{\partial \theta}{\partial t}
$$

Equation 58 becomes

$$
\frac{\partial \theta}{\partial t}=\frac{\partial}{\partial x}\left[D_{\theta_{v e}}(\theta) \frac{\partial \theta}{\partial x}\right]
$$

which is identical in form to Equation 38. By only measuring soil water contents within a soil column, a separation of that water moving as vapor and that as liquid cannot be achieved. Hence, we rewrite Equation 59 as

$$
\frac{\partial \theta}{\partial \mathrm{t}}=\frac{\partial}{\partial \mathrm{x}}\left[\mathrm{D}_{\theta_{\mathrm{v}}}(\theta) \frac{\partial \theta}{\partial \mathrm{x}}\right]
$$

where $D_{\theta_{v}}$ accounts for both vapor and liquid transfers and is defined as

$$
D_{\theta_{v}}(\theta)=D_{\theta_{v \theta}}+D_{\theta_{u q}}
$$

Jackson used pressure dependence of $D_{\theta_{v a}}$ to ascertain the relative magnitudes of $D_{\theta_{v e q}}$ and $D_{\theta_{\text {nq }}}$ 
The experimental set-up to study water vapor diffusion is shown at the top of Figure 19. A homogeneous soil initially at water content $\theta_{n}$ was subjected to a constant vapor density at $\mathrm{x}=0$. The constant vapor density at $x=0$ gives rise to a constant soil water content $\theta_{0}$ If $\theta_{0}>\theta_{n}$, the soil absorbs water. If $\theta_{0}<\theta_{n}$, the soil loses water. The top graph in Figure 19 shows soil water content profiles of a soil having $\theta_{\mathrm{n}}=0.02 \mathrm{gg}^{-1}$ and being subjected to $\theta_{0}=0.05 \mathrm{gg}^{-1}$ for times of 7,135 and $12,945 \mathrm{~min}$ (about 5 and $9 \mathrm{~d}$ ). Water moves into these soil columns. The bottom graph in Figure 19 shows soil water content profiles of a soil having $\theta_{n}=0.06 \mathrm{gg}^{-1}$ and being subjected to $\theta_{0}=$ $0.01 \mathrm{gg}^{-1}$ for times of 10,260 and $20,020 \mathrm{~min}$ (about 7 and $14 \mathrm{~d}$ ). Water moves out of these soil columns.

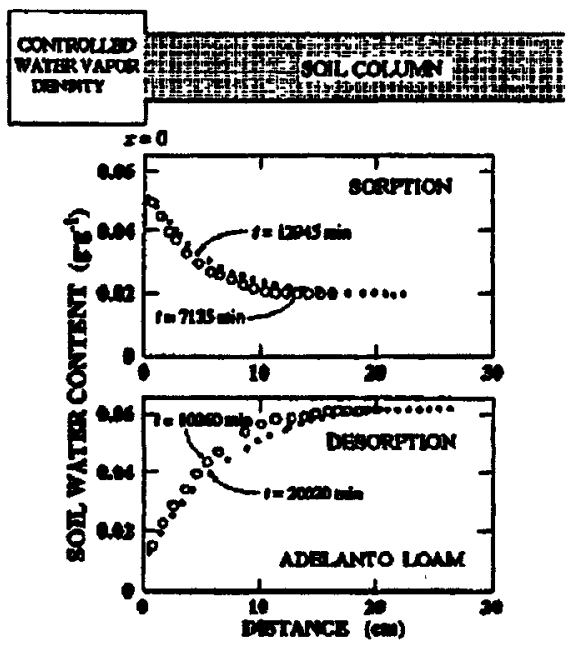

Figure 19 - Experimental apparatus to observe water vapor transport and measured soil water content profiles for two different times of sorption and desorption, respectively.

The graphs in Figure 20 show that these respective soil water profiles at different times are coalesced into one curve by the Boltzmann transform Equation 39. Figure 21 shows the relative amounts of vapor and liquid transported during under isothermal conditions. Figure 22 shows the temperature dependence of $\mathrm{D}_{\theta_{\mathrm{v}}}$

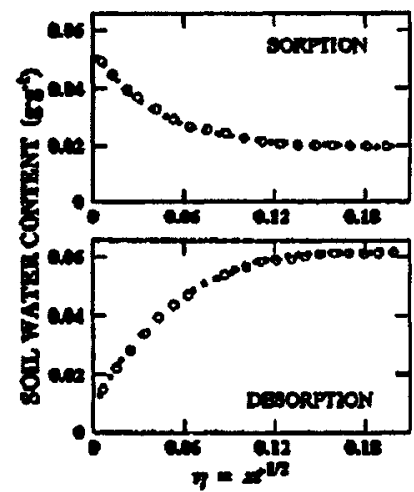

Figure 20 - Soil water content profiles of Figure 19 scaled with Boltzmann transformation.

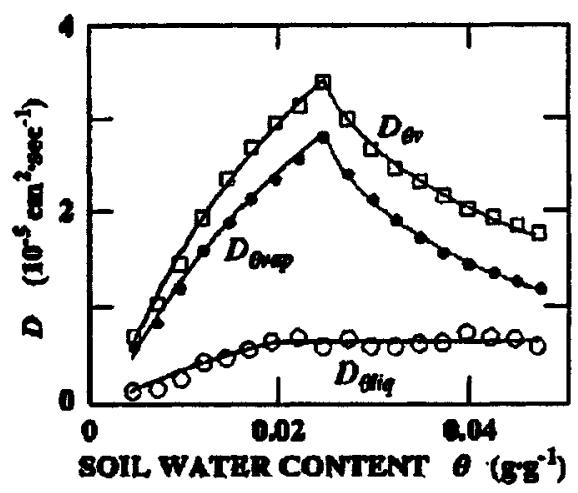

Figure 21 - Total, vapor and liquid diffusivity functions of soil water content for $25^{\circ} \mathrm{C}$ for Adelanto loam.

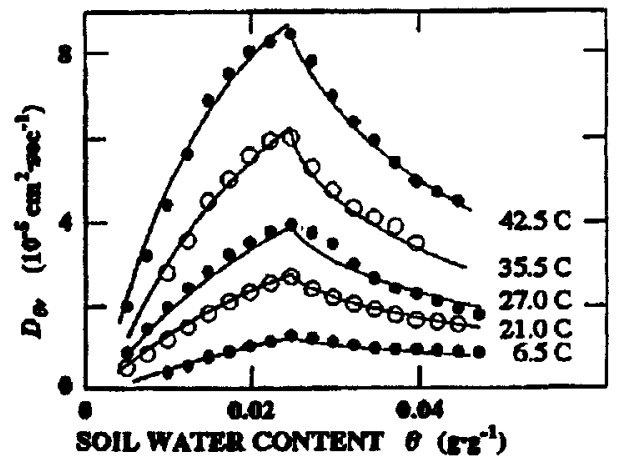

Figure 22 - Temperature dependence of total diffusivity functions of soil water content for Adelanto loam. 


\section{TRANSPORT OF SOLUTES IN SOILS}

First we consider the physical and chemical interactions of solutes that play an important role in soil salinity and fertilizer management.

\section{SOLUTE INTERACTIONS}

Molecular Diffusion: Thermal energy provides a continual, never ending movement of liquid phases of the soil system. Owing to molecular diffusion, solutes in the soil solution obey Fick's first law similar to that of Equation 54 above for water vapor diffusion. For solute diffusion, the solid matrix of the soil complicates matters by altering both the diffusion path length and the cross sectional area available for diffusion as well as providing an electric field and reactive surfaces that further alter molecular movement. The steady state solute flux density is given by

$$
q_{\text {solute }}=-D_{m} \frac{d C}{d x}
$$

where $D_{m}$ is the molecular diffusion coefficient and $C$ the concentration of the solute.

Electric Force Fields: Electric force fields always exist within the pore structure of soils owing to the electric charge possessed by the walls of soil pores. The charge per unit pore wall area is caused by isomorphous substitution of atoms in the tetrahedral and octahedral layers of the clay minerals as well as the presence of the Si-O-H (silanol) group on quartz, kaolin minerals and other surfaces like organic matter $(-\mathrm{OH}$ and $-\mathrm{COOH}$ ). The magnitude of the former is fixed while that of the latter depends upon $\mathrm{pH}$ and concentration of the soil solution. In general, small highly charged ions cause the viscosity of the soil solution to increase while large monovalent ions cause the viscosity to decrease. The electrostatic fields of the ions cause polarization and a binding of surrounding water molecules which alter the kinetic properties of soil water. The hydrophilic nature of most soil particles is attributed to the attraction of hydrated cations by the electrostatic field of soil particles and to the hydrogen bonding of water to the clays (Low, 1961). The mobility of both water and ions in the region of the pore walls is reduced below that in bulk solutions (Kemper, 1960; Dutt \& Low, 1962). The impact of the electric field on ions and water is more pronounced in clayey soils and depends upon the ionic concentration and distance from the pore wall.

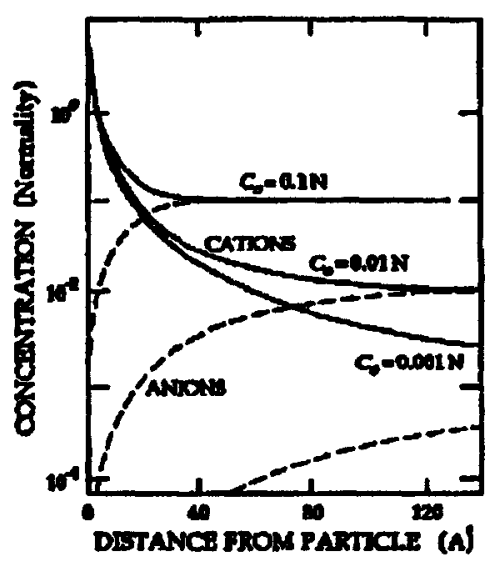

Figure 23 - Distributions of cations and anions in the vicinity of a clay particle surface for three different solution concentrations.

The distribution of cations as a function of distance from a negatively charged flat surface is explained by the electrostatic force causing cations to move toward the surface is counteracted by the thermal motion of the solutes causing them to diffuse away from the surface. We see in Figure 23 that the extent of the unequal distribution of cations and anions away from the surface depends inversely upon the total concentration $\mathrm{CO}$ of the solution. And, we note from Fig 24 for cylindrical pores with a wall having a net negative charge and filled with a solution of concentration $\mathrm{CO}$ that the concentration distribution across the pores depends upon the magnitude of the pore radius. In the center of large pores the concentrations of cations and anions are identical while in the center of small pores owing to the electric field, the cationic concentration exceeds that of anions.

As water moves through pores, cations and anions unequally distributed across the pores because of the negatively charged pore walls are swept along with the water. Consequently, a differential charge builds up along the length of flow which tends to retard water flow. This 
differential charge is called streaming potential. Similarly, if an electrical potential difference is established across a soil, ions moving within the electric field will create a water flux. Each process contributes to the behavior of solutes and water at the pore scale and offers an opportunity for understanding and managing solute movement and retention in soil profiles.

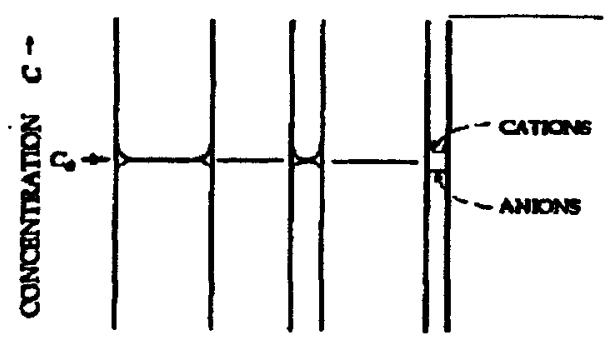

Figure 24 - Distributions of cations and anions within capillary tubes having three different radii.

Other Interactions: Constituents in the gas, liquid and solid phases of soil continually reacting with each other through a variety of chemical and biological pathways contribute to the presence and behavior of particular solutes in soil profiles. Applicable equilibrium and non-equilibrium chemical concepts are those of oxidationreduction, solubility-precipitation, associationdissociation, acid-base and exchange-adsorption. Microbiological reactions as well as those involving root systems of higher plants contribute to the behavior of solutes in field soils. A full understanding of solute transport begins with a knowledge of the above interactions.

Miscible Displacement: The term miscible displacement refers to the process of one fluid miscible with another invading and displacing the latter. With the fluids being miscible, they are able to completely mix, dissolve and dilute each other. Here after considering miscible displacement in a capillary tube without molecular diffusion, we progress to laboratory experiments displacing solutes having different kinds of soil that undergo various chemical and physical reactions. Simple theoretical concepts are used to explain the results. Our understanding of processes occurring during miscible displacement will be illustrated during the workshop with measurements of leaching and fertilizer movement in field soils.

In a Single Capillary without Diffusion: From the definition of viscosity, the velocity distribution of a liquid within a capillary tube of radius a during steady, uniform flow is derived to be the well-known parabolic velocity distribution

$$
v(r)=2 v_{0}\left(1-\frac{r^{2}}{a^{2}}\right)
$$

where $v(0)=2 v_{0}$. The average velocity $v$ of the liquid is vo. Integrating $v(r)$ with the areal crosssection of the capillary, the volumetric flow rate $\mathrm{Q}\left(\mathrm{cm}^{3} \mathrm{~s}^{-1}\right)$ through the capillary is

$$
\mathrm{Q}=\frac{\mathrm{a}^{4} \pi \Delta \mathrm{P}}{8 \eta \mathrm{L}}
$$

If we rely solely on Equation 63 to describe the fluid velocity, what will be the distribution of a second fluid of concentration $\mathrm{CO}$ as it displaces a fluid of zero concentration initially within the capillary of length L? Assume that the solution $\mathrm{CO}$ enters the tube at $\mathrm{x}=0$ at time $t=0$. The concentration $C$ averaged over the cross section of the capillary at distance $x$ is

$$
C_{a}=\frac{1}{\pi \mathrm{a}^{2}} \int_{0}^{\mathrm{e}} 2 \pi \mathrm{rC}(\mathrm{r}) \mathrm{dr}
$$

or as a function of distance and time is

$$
C_{a}(x, t)=C_{0}\left(1-\frac{x}{2 v_{0} t}\right)
$$

In Figure 25, the i paraboloid of the displacing fluid $\mathrm{CO}$ within the capillary gives rise to a linear concentration distribution. When the invading front of $\mathrm{CO}$ has reached a distance $2 \mathrm{~L}$, the average concentration across the plane normal to the capillary at a distance of $\mathrm{L}$ is $\mathrm{Co} / 2$. Interestingly, the average concentration of the fluid moving across the plane $\mathrm{L}$ at that instant is not $\mathrm{Col} 2$ but $3 \mathrm{Co} / 4$. The average concentration of fluid moving past $\mathrm{x}=\mathrm{L}$ (see Figure 26a) is 
$C_{1}=\frac{\text { mass of solute moving past } x=L}{\text { volume of fluid moving past } x=L}$
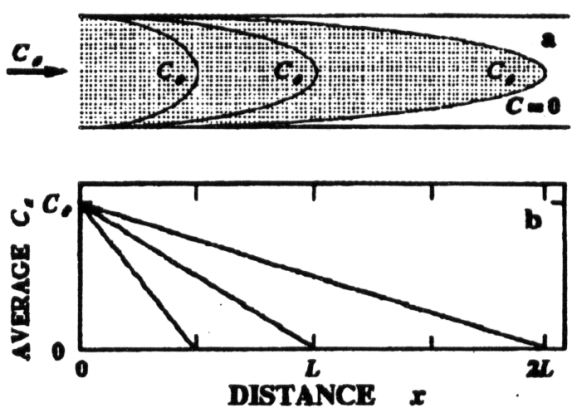

Figure 25 - Parabolic velocity distributions of an invading solution $C_{0}$ within a capillary tube give rise to linear average concentrations along the tube (Equation 66).
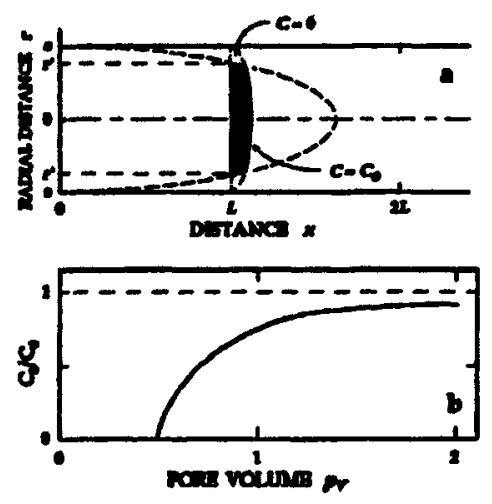

Figure 26 - a. Diagram of an elementary volume of liquid moving within a capillary tube. b. Average relative concentration of liquid leaving a capillary tube of length $L$ as a function of pore volume (Eq. 69).

Eq. 67 leads to

$$
\begin{aligned}
C_{0}(t) / C_{0}=0 & v_{0} t / L \leq 0.5 \\
=1-L^{2} / 4 v_{0}^{2} t^{2} & v_{0} t / L>0.5
\end{aligned}
$$

or

$$
\begin{array}{cr}
C(p) / C_{0}=0 & p \leq 0.5 \\
=1-L^{2} / 4 p^{2} & p>0.5
\end{array}
$$

where $p=v_{0} t / L$ and is the ratio of the volume of fluid passing $\mathrm{X}=\mathrm{L}$ to the volume of the capillary between $\mathrm{O} \leq \mathrm{x} \leq \mathrm{L}$. Pore volume of effluent or simply pore volume is the name commonly used for $p$. The value of $c=3$ Col4 for $p=1$ and approaches unity as $p \rightarrow \infty$, see Figure $26 \mathrm{~b}$. Even for such a simple geometry as a capillary tube, the concentration distribution within the tube (Figure $25 \mathrm{~b}$ ) is not easily reconciled with the shape of the concentration elusion curve (Figure 26b).

Convective Transport of Solutes: The spreading or dispersion of the solute caused by convective transport with the water can be qualitatively visualized in Figure 27 for a simplified soil. The invading stream of solute partitions itself according to the microscopic pore water velocities occurring between the soil particles. At still a smaller scale, the water velocity is zero at the particle surface, departs markedly from the mean flow direction and approaches a zero value in the vicinity of dead-nd pores. These pathways and pore water velocities, severely altered with slight changes of water content, have yet to be quantitatively evaluated. In the near future, computer-aided micro tomography and nuclear magnetic resonance techniques will provide an opportunity to ascertain the exact nature of the velocities at the pore scale.

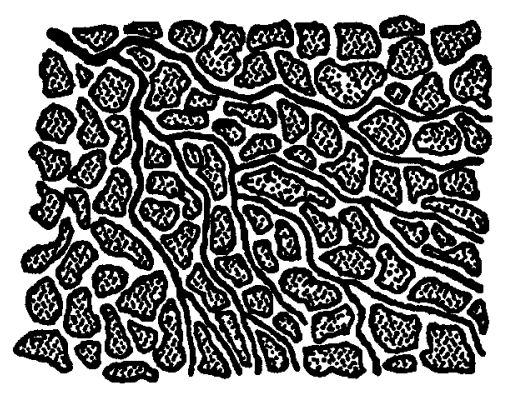

Figure 27 - Spreading or dispersion of a solute caused by convective transport in a simplified soil.

For water infiltrating into a deep, homogeneous, water-saturated soil, we see in Figure 28 that a solute of concentration $C_{0}$ 
maintained at a point on the soil surface is dispersed vertically and horizontally. The velocity of the soil solution varies in both magnitude and direction owing to the distribution of irregularly shaped pores within the soil. Along transect A-A', the initial concentration $C_{o}$ at $z=0$ gradually diminishes to zero. Similarly, the concentration distribution normal to the average flow along transect B-B' gradually broadens with soil depth.

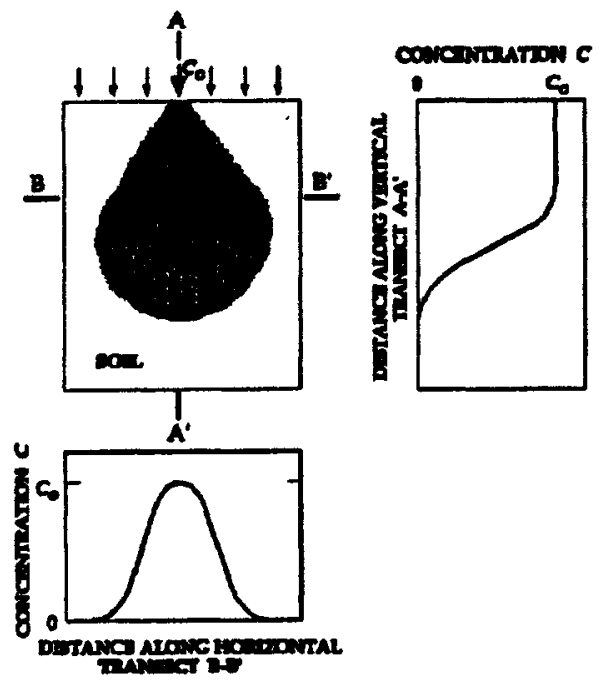

Figure 28 - A solution of concentration $\mathrm{C}_{0}$ being introduced at one point on the surface of a uniform, water-saturated soil during steady state infiltration.

Laboratory Observations: One dimensional soil columns studied in the laboratory provide a simple means of quantifying the mixing, spreading or attenuation of the solute schematically presented in Figure 28. An apparatus is required to maintain steady state flow and invariant soil water content conditions when the initial soil solution is invaded and eventually displaced by a second miscible solution. No mixing of the two solutions should occur at their boundary before entering the soil column, and samples of effluent to be analyzed for solute concentration has to be collected without disturbing the steady state flow conditions. A cross sectional sketch of a typical apparatus is given in Figure 29.
Breakthrough Curves: Let the volume of the soil column occupied by soil solution be $V_{0}$ and the rate of inflow and outflow of the soil solution be $Q$. If the initial soil solution identified by a solute concentration $C_{1}$ is suddenly displaced by an incoming solution $\mathrm{C}_{0}$, the fraction of this incoming solute in the effluent at time $t$ will be $\left(C-C_{1}\right)\left(C_{0}-C_{1}\right)$, or for an initial concentration of zero, simply $\mathrm{C} / \mathrm{C}_{\mathrm{o}}$. Plots of $\mathrm{C} / \mathrm{C}_{\mathrm{a}}$ versus pore volume of effluent $\left(Q t / V_{0}\right)$, commonly called breakthrough curves, describe the relative times taken for the incoming solution to flow through the soil column. Note that the definition of pore to all soil water contents. Any experimentally measured breakthrough curve may be considered one or a combination of any of the five curves shown in Figure 30.

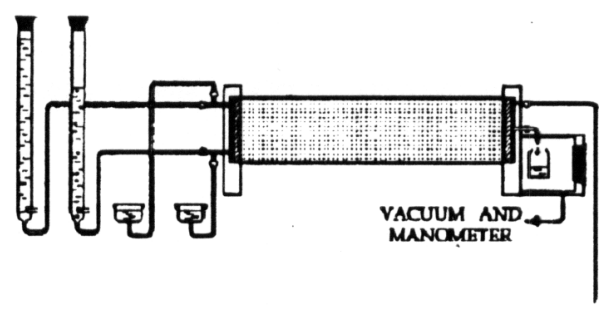

Figure 29 - Laboratory apparatus for conducting miscible displacement experiments with soil columns.

For Figure 30a-c, the solute spreads only as a result of molecular diffusion and microscopic variations of the velocity of the soil solution, $i$. e. there is no interaction between the solute, water and soil particle surfaces. In these cases

$$
\frac{Q}{V_{0}} \int_{0}^{\infty}\left(1-\frac{C}{C_{0}}\right) d t=1
$$

regardless of the shape of the curve. This equation expresses the fact that the original soil solution occupied exactly one pore volume or that the quantity of solute within the soil column that will eventually reach a chemical equilibrium with that in the influent and effluent is $C_{0} V_{0}$.

Note also that the area under the breakthrough curve up to one pore volume (area $A$ in Figure $30 \mathrm{~b}$ and $c$ ) equals that above the 

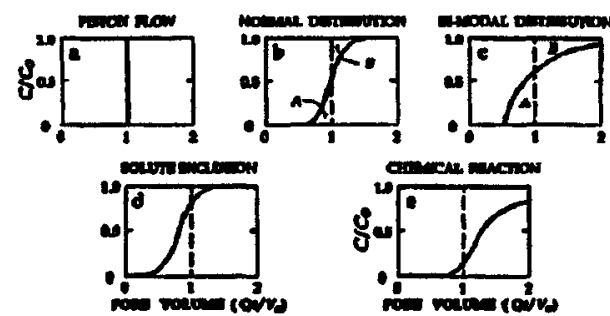

Figure 30 - Types of breakthrough curves for miscible displacement $\mathrm{C} / \mathrm{CO}$ is the relative concentration of the invading fluid measured in the effluent and pore volume is the ratio of the volume of effluent to the volume of fluid in the sample.

curve for all values greater than one pore volume (area B), regardless of the shape of the curve. This latter statement is a direct result of Equation 30 , i.e.

$$
\frac{Q}{V_{0}} \int_{0}^{\frac{V_{0}}{Q}} \frac{C}{C_{0}} d t=\frac{Q}{V_{0}} \int_{\frac{V_{0}}{Q}}^{\infty}\left(1-\frac{C}{C_{0}}\right) d t
$$

Danckwerts (1953) defined holdback $\mathrm{H}_{b}$ as the left hand term of Equation 71 having a range $0<\mathrm{Hb}<1$ for non reacting solutes. The concept of holdback is a useful qualitative description whenever interactions between solute, water and soil solids are minimal. It indicates the amount of the soil water or solutes not easily displaced. Values of $\mathrm{H}_{b}$ for unsaturated soils have been evaluated to be 3 to 4 times greater than those for saturated soils.

Piston flow (Figure 30a) never occurs owing to solute mixing that takes place by molecular diffusion and variations in water velocity at the microscopic level within soil pores. The breakthrough curve shown in Figure 30b is characteristic of the longitudinal spreading of a solute as it is displaced through a soil having a normally distributed sequence of pores. Evidence for lack of solute-solid interaction is the fact that the areas A and B described by (71) are identical. A water-saturated soil composed of equal-sized aggregates manifesting a bimodal pore water velocity distribution typically yields the breakthrough curve given in Figure 30c. With the areas $A$ and $B$ of this curve being comparable, any interaction between the solute and the soil particles is negligible.

An appearance of a breakthrough curve to the left of one pore volume as shown in Figure $30 d$ (area $A>$ area $B$ ) results from the incoming solution not displacing water in stagnant and deadend pores or the incoming solute being repelled from the soil particle surfaces as in the case of a anion passing in the vicinity of a negatively charged soil particles. A solute having a large diffusion coefficient mixes more completely with the water in stagnant and slowly conducting zones, thus delaying its appearance in the effluent. It should not be expected that the relative behavior of solutes be the same for all velocities and different soils. For example, if one solute has a diffusion coefficient much greater than the other, it would be possible for it to not only invade the nearly stagnant zones but also diffuse downstream ahead of the other solute. In this case the faster diffusing solute will appear in the effluent earlier that the more slowly diffusing solute. An appearance of a breakthrough curve to the right of one pore volume as shown in Figure 30 e (area $A<$ area $B$ ) results from adsorption and exchange of the solute on the soil particle surfaces as well as a chemical reaction in the soil that serves as a sink for the incoming solute. Unsaturating a soil alters the pore water velocity distribution, allows some of the solute to arrive downstream earlier and increases the magnitude of holdback manifested by area $A$ in Figure 30. Desaturation eliminates larger flow channels and increases the volume of water within the soil which does not readily move. These almost stagnant water zones act as sinks to molecular diffusion. Later we shall discuss the opportunity afforded by controlling the water content and pore water velocity to change the leaching efficiency of field soils.

A Theoretical Description: Several different kinds of theories have been proposed and equations derived to describe solute transport in both inert and reactive porous media. A comprehensive treatment would include transfers of the solute in all three phases of the soil - gas, liquid and solid. Here we consider the cornerstone of most theoretical descriptions - the convective-diffusion equation. Although it is commonly used to describe miscible displacement, it is nevertheless fraught with difficulties and approximations not easily resolved in the laboratory or the field. 
We begin with a prism element having edges of length $\Delta x, \Delta y$ and $\Delta z$. The difference between the mass of solute entering the prism and that leaving the prism equals the difference of the solute stored in the prism in time $\Delta t$ providing that we account for any appearance (source) or disappearance (sink) of the solute within the prism by mechanisms other than transport. The solute flux density into the prism in the direction of the $\mathrm{x}$ axis is $\mathrm{J}_{\mathbf{x}}$. If we assume the change in $\mathrm{J}_{\mathrm{x}}$ is continuous, the solute flux density out of the prism in the same direction is $\left[\mathrm{J}_{\mathrm{x}}+\left(\partial \mathrm{J}_{\mathrm{x}} / \partial \mathrm{x}\right) \Delta \mathrm{x}\right]$. The solute mass into the prism is $J_{x} \Delta y \Delta z \Delta t$ and that out of the prism is $\left[\mathrm{J}_{\mathrm{x}}+\left(\partial \mathrm{J}_{\mathrm{x}} / \partial \mathrm{x}\right) \Delta \mathrm{x}\right] \Delta \mathrm{y} \Delta \mathrm{z} \Delta \mathrm{t}$. The difference between the mass into and out of the prism is

$$
\mathrm{J}_{\mathrm{x}} \Delta \mathrm{y} \Delta \mathrm{z} \Delta \mathrm{t}-\left[\mathrm{J}_{\mathrm{x}}+\left(\frac{\partial \mathrm{J}_{\mathrm{x}}}{\partial \mathrm{x}}\right) \Delta \mathrm{x}\right] \Delta \mathrm{x} \Delta \mathrm{y} \Delta \mathrm{z}(72)
$$

or

$$
-\left(\frac{\partial J_{x}}{\partial x}\right) \Delta x \Delta y \Delta z \Delta t
$$

Similar equations are derived for the directions of the $y$ and $z$ axes. The sum of the differences in three directions equals the change of the solute content of the prism. Provided that the total mass of solute associated with both the liquid and solid phases per unit volume of prism $S(t)$ has a continuous derivative for $t>0$, we obtain the equation of continuity

$$
\frac{\partial \mathrm{S}}{\partial \mathrm{t}}=-\left(\frac{\partial \mathrm{J}_{\mathrm{x}}}{\partial \mathrm{x}}+\frac{\partial \mathrm{J}_{\mathrm{y}}}{\partial \mathrm{y}}+\frac{\partial \mathrm{J}_{\mathrm{z}}}{\partial \mathrm{z}}\right)
$$

If we further take into consideration irreversible sources or sinks (i occurring within the prism during the time period over which the equation applies, we have

$$
\frac{\partial S}{\partial t}=-\left(\frac{\partial J_{x}}{\partial x}+\frac{\partial J_{y}}{\partial y}+\frac{\partial J_{2}}{\partial z}\right)+\sum_{i} \phi_{i}
$$

In general, soil solutes exist in both gaseous and aqueous phases as well as being associated with the solid organic and inorganic reside in soils and participate in the displacement process. We have also assumed that the solutes in the soil solution are not volatile and have ignored their content and transport in the gaseous phase. Hence, the total solute concentration $S$ in Equation 75 is

$$
S=\rho_{\mathrm{T}} \mathrm{C}_{\mathrm{S}}+\theta \mathrm{C}
$$

where $\rho_{T}$ is the soil bulk density, $C_{S}$ the solute adsorbed or exchanged on the soil solids and $\mathrm{C}$ the solute in solution.

The solute flux density $\mathrm{J}$ in Equation 75 relative to the prism $\Delta x \Delta y \Delta z$ is difficult to define unambiguously owing to the fact that the representative elementary volumes of each of the terms in $J$ and $S$ are not necessarily equal nor known, particularly for structured field soils. Each of the directional components of $J$ is comprised of contributions of solute movement within the liquid phase as well as along particle surfaces of the solid phase. We assume that solute movement along soil particie surfaces is nil or can be accounted for by functions relating the concentration of solutes in solution to that associated with the solid phase in Equation 76. Hence, the solute flux density consists of two terms, one describing the bulk transport of the solute moving with the flowing soil solution and the second describing the solute moving by molecular diffusion and meandering convective paths within the soil solution. For the z-direction, we have

$$
J_{z}=q_{z} C-\theta\left(D_{c_{z}}+D_{m_{z}}\right) \frac{\partial C}{\partial z}
$$

where $q_{z}$ is the Darcian soil water flux, DC and $\mathrm{Dm}$ are the coefficients of convective dispersion and molecular diffusion in the soil solution, respectively. Equations for $J_{x}$ and $J_{y}$ are identical to Equation 77 when $\mathrm{z}$ has been replaced by $\mathrm{x}$ and $y$, respectively. We continue the analysis here for only the vertical soil profile direction.

Substituting Equations 76 and 77 into Equation 75 , we obtain for a solute of the soil solution that does not volatilize into the soil air 


$$
\begin{aligned}
& \frac{\partial\left(\rho_{r} C_{s}\right)}{\partial}+\frac{\partial(\theta C)}{\partial}= \\
& =\frac{\partial}{\partial}\left[\theta\left(D_{c}+D_{m}\right) \frac{\partial C}{\partial z}\right]-\frac{\partial(q C)}{\partial z}+\sum_{1} \phi_{i}
\end{aligned}
$$

The first term of Equation 78 describes the rate at which a solute reacts or exchanges with the soil solids. With $D_{a}=\left(D_{c}+D_{m}\right)$, Equation 78 reduces to

$$
\begin{aligned}
& \frac{\partial\left(\rho_{T} C_{s}\right)}{\partial t}+\frac{\partial(\theta C)}{\partial t}= \\
& =\frac{\partial}{\partial z}\left[\theta D_{a} \frac{\partial C}{\partial z}\right]-\frac{\partial(q C)}{\partial z}+\sum_{i} \phi_{i}
\end{aligned}
$$

The source-sink term $\phi_{\mathrm{i}}$ in Equation 78 or Equation 79 is often approximated by zero or first-order rate terms

$$
\phi_{i}=\gamma \theta+\gamma_{s} \rho+\mu \theta C+\mu_{s} \rho_{T} C_{S}
$$

where $\gamma$ and $\gamma_{s}$ are rate constants for zero-order decay or production in the soil solution and solid phases, respectively, and $\mu$ and $\mu_{6}$ are similar first-order rate constants for the two phases. For radioactive decay, physicists may safely assume that $\mu$ and $\mu_{3}$ are identical as well as assuming that both $\gamma$ and $\gamma_{3}$ are nil. Microbiologists, considering organic and inorganic transformations of soil solutes in relation to growth, maintenance and waste metabolism of soil microbes as a Michaelis-Menten process, often simplify their considerations to that of ( $i$ in Equation 80. McLaren (1970) provided incentives to study such reactions as functions of both space and time in soil systems - a task not yet achieved by soil microbiologists, especially when the individual characteristics of each microbial species is quantified and not lumped together as a parameter of the entire microbial community. Agronomic or plant scientists consider ( $i$ as an irreversible sink and source of solutes taking place in the vicinity of the rhizosphere of cultivated or uncultivated plants as a function of soil depth and time as well as some empirical function defining the root distribution.

For a solute that does not appreciably react with the soil particles, does not exist in the soil air and does not appear or disappear in sources or sinks, respectively, Equation 79 reduces to

$$
\frac{\partial C}{\partial t}=\frac{\partial}{\partial z}\left(\mathrm{D}, \frac{\partial C}{\partial z}\right)-\frac{\partial(\mathrm{vC})}{\partial z}
$$

For steady state flow in a homogeneous soil at constant water content, Equation 81 reduces still further to

$$
\frac{\partial C}{\partial t}=D_{a} \frac{\partial^{2} C}{\partial z^{2}}-v \frac{\partial C}{\partial z}
$$

which has been extensively used to develop empirical relations between the apparent diffusion coefficient $D_{a}$ and the average pore water velocity $\mathbf{v}$.

Numerical and analytical solutions for the above equations subject to initial and boundary conditions are available and will be discussed in the lectures of the course for selected laboratory and field experiments.

Theoretical Implications: The majority of inorganic cations, anions and solutes in soil solutions have diffusion coefficients in the order of $10^{-5} \mathrm{~cm}^{2} \cdot \mathrm{s}^{-1}$ while organic cations, anions and solutes usually manifest much smaller values. These coefficients are moderately temperature dependent and slightly concentration dependent. The importance of their different magnitudes is apparent only at relatively small pore water velocities.

The existence of concentration gradients of inorganic salts in the soil solution responsible for solute transfer by diffusion or as a result of convection guarantees that the displacing and displaced solutions do not generally have identical values of density or viscosity no matter how close their values. In soils, it is not uncommon to experience solutions of unequal density and viscosity. During the extraction of water from soil profiles by plants or by evaporation at the soil surface, the density and viscosity of the soil solution increase continually. Conversely the infiltration of rain or many irrigation waters causes the soil solution to be diluted. Fertilizers and other agrochemicals also alter these properties of the soil solution. The density and viscosity of the soil solution also differ from those of the bulk solution owing to the 
interaction of water and the soil particle surfaces especially in unsaturated soils or chose soils having large clay contents.

Although arid soils usually are dominated by constant charge colloids and tropical soils by chose of constant potential, all soils are mixtures of both, and hence $\mathrm{pH}$ cannot be ignored. For soils containing substantial amounts of clay having a variable surface charge, the $\mathrm{pH}$ will depend upon solute concentration. For such soils differences in leaching characteristics are a result of the concentration of the soil solution rather than strictly being caused by hydrodynamic and geometric aspects of the flow regime.

The mixing and attenuation of a solute by convection depend upon the pore size distribution and the number of bifurcations experienced by the soil solution as water flows through its system of microscopic pores (recall Figure 27). The greater the total macroscopic displacement length, the greater will be the opportunity for both convective and diffusive mixing. As the displacement length increases, both the number of bifurcations in the pore system and the time for molecular diffusion increase. Hence the deeper the displacement, the greater the spreading of the solute.

Soll and Water Management Implications: Although our understanding and theoretical description of solute transport in soils remain incomplete, we have nevertheless sufficient knowledge to derive a few principles or guidelines for managing solute retention or leaching in the field. Whether solutes accumulate or leach depends primarily upon the processes by which they enter, react and leave the soil profile relative to their association with water. Summarizing the more important points of this section regarding the relative movements of soil water and its dissolved constituents, we make the following conclusions: a. As water moves more slowly through a soil, there is a greater opportunity for more complete mixing and chemical reactions to take place within the entire microscopic pore structure owing to the relative importance of molecular diffusion compared with that of convection. b. Microscopic pore water velocity distributions manifest their greatest divergence for water-saturated soil conditions. Hence, under water-saturated conditions, the greatest proportion of water moving through the soil matrix occurs within the largest pore sequences. c. Under water-saturated soil conditions, when the average pore water velocity is large compared with transport by molecular diffusion, the relative amount of solute being displaced depends upon the solute concentration of the invading water. $d$. The concept of preferential flow paths occurs at all degrees of water-unsaturation even though their existence is usually only demonstrated for macropores near water-saturation. At each progressively smaller water content, the larger pore sequences remaining full of water establish still another set of preferential flow paths. e. Any attempt to measure the solute concentration based on extraction methods carried out either in the laboratory or the field will be dependent upon the rate of extraction and the soil water content during the extraction process. f. Inasmuch as rainfall infiltration usually occurs at greater soil water contents and greater average pore water velocities than does evaporation at the soil surface, the amount of solutes transported near the soil surface per unit water moving through the soil surface is greater for evaporation than for infiltration.

\section{STATISTICAL CONCEPTS}

Classical Statistical concepts: In classical statistics used commonly in the agricultural sciences, only the magnitudes of the observations are involved in the calculations while their coordinate values of space (or time) are frequently neglected. For example, observations of soil nitrogen taken in differently treated plots are expressed as

$$
z(i, j)=\mu+\rho(j)+\varepsilon(i, j)
$$

where $\mathrm{Z}$ is the ith observation of treatment having an expected mean $\mu$, treatment deviation $\sigma$ and an error $\varepsilon$. Usually, the probability distribution of the observations is assumed to be known without adequate experimental verification, and an analysis of variance conducted to ascertain the magnitude of a perturbation caused by a particular treatment.

Spatially Related Observations: An observation of a soil or crop attribute can also be considered in the form 


$$
Z(x)=\mu+p(x)
$$

where $\mathrm{X}$ is the spatial coordinate (in 1,2 or 3 space dimensions or that of time). The value of $\mu$ across the landscape need not be constant and observations $\mathrm{Z}$ will reflect both local and regional variations as well as depending on sample size. This latter concept, being able to sample different attributes of the landscape over different scales of space and time, provides a panacea of new field research opportunity for crop and soil scientists. There has been already a remarkable amount of research in agriculture and agroecology using this regionalized variable approach to analyze anthropogenic activities or those occurring naturally within various kinds of ecosystems. Excellent texts are available to explain the assumptions upon which the theories and methods are based as well as the limitations of their application to a particular situation (e.g., Clark, 1979; Davis, 1973; Journel and Huijbregts, 1978; Shumway, 1988; and Webster and Burgess, 1983).

Autocorrelation: A concept fundamental to geostatistics and regionalized variable analysis is that of spatial dependence of soil or crop attributes. Intuitively, we do not expect field observations of soil properties to be necessarily spatially independent. We would expect measurements made close together to yield nearly equal values, and measurements made a small distance apart to yield values correlated with each other. We would also expect a partially repetitious behavior of soil observations as a result of cyclic tillage traffic and cropping patterns in cultivated fields, sequences of low and high topographical positions giving rise to cyclic locations of greater and lesser degrees of leaching, and sequences of soil mapping units not randomly located within a landscape owing to soil formation processes that are linked spatially to the coordinates of the soil surface. We describe and illustrate below the concepts of spatial dependence and probability distributions of observations which are often confused and confounded by soil and crop scientists.

A measure of the strength of the linear association between pairs of observations is useful in defining the separation distance between observations beyond which there is no correlation between pairs of values. This concept of spatial dependence or autocorrelation is helpful to answer the question, "How far apart should observations be taken, how large an area is represented by a single observation, or what size of observation is most appropriate?" Similar questions in time are also relevant. Consider a set of $n$ observations $O(x)$ taken along a unidirectional transect across a field at a spacing $h\left(h=x_{i+1}-x_{i}\right)$. Analogous to calculating the linear regression coefficient $r$ for a set of measurements of crop yield as a function of applied nitrogen fertilizer, the spatial auto correlation coefficient $r$ is calculated from

$$
\begin{aligned}
& r(h)=\operatorname{cov}[O(x+h), O(x)] \\
& \{\operatorname{var}[O(x+h)] \operatorname{var}[O(x)]\}^{-\frac{1}{2}}
\end{aligned}
$$

where cov is covariance and var is variance. When observations $O$ are taken 1 unit apart, $r(1)$ is the value of the linear regression coefficient for $h=1$ (lag 1) when values of $O(x+1)$ are plotted against values of $O(x)$. In other words, nearest neighbors are plotted against each other. Similarly, when $h=2, r(2)$ is the value of the coefficient when values of $O$ are plotted against other values observed a distance of 2 units away.

The functional relation $\mathbf{r}(\mathrm{h})$ has been expressed with several empirical formulae. One of the most commonly used expressions is

$$
r(h)=\exp \left(-\frac{h}{\lambda}\right)
$$

where $\lambda$ is selected in order that the sum of the measured deviations of $r$ from the above expression is zero. Note that the value of $\lambda$ is equal to that distance $h$ between measured values for which their correlation coefficient is $V / e . \lambda$ is called the autocorrelation length or the scale of observation. A liberal interpretation of $\lambda$ is that it represents the radial distance within a field characterized by a single observation.

Figure 3la presents soil water content $\theta$ measured in a field at $1 \mathrm{~m}$ intervals with a neutron moisture meter at the $50 \mathrm{~cm}$ soil depth within a $160 \mathrm{~m}$ long transect. Neglecting the locations of the observations ( $n=160$ ), Figure $31 \mathrm{~b}$ is a histogram showing that the mean $\mathrm{m}$ and standard deviation $s$ of the 160 observations are 
0.136 and $0.0162 \mathrm{~cm}^{3} \cdot \mathrm{cm}^{-3}$, respectively. The height of each vertical bar represents the number of observations found in a range $A B$ of 0.01 $\mathrm{cm}^{3} \cdot \mathrm{cm}^{-3}$. The smooth curve shown in the figure is for a normal probability density function equation

$$
N=n \Delta \theta(2 \pi s)^{-1 / 2} \exp \left[-\frac{(\theta-m)^{2}}{2 s^{2}}\right]
$$

where $\mathrm{N}$ is the number of observations of $\theta$ within $\theta \pm 2^{-1} \Delta \theta$. Having concluded that these observations are normally distributed, it is possible to ascertain the number of observations required to estimate the mean soil water content across the transect within prescribed levels of probability. On the other hand, the above formula says nothing about how far apart the observations should be taken. Figure $31 \mathrm{c}$, the autocorrelogram of the 160 observations, shows that the autocorrelation length $\lambda$ is about $6 \mathrm{~m}$. Sampling at intervals less than $6 \mathrm{~m}$ is somewhat unnecessary because the observations are related to each other. Sampling at intervals greater than $6 \mathrm{~m}$ does not allow meaningful interpolation between neighboring observations. It should be obvious that the functional relation between $r$ and $h$ depends upon the size of the sample, and that in general' the greater the sample size, the greater the value of the autocorrelation length $X$. For any particular study, the investigator should consider the minimum distance between sampling locations $(h=1)$ in relation to the objectives of the experiment and the potential utility of the values of $\lambda$ for each kind of observation.
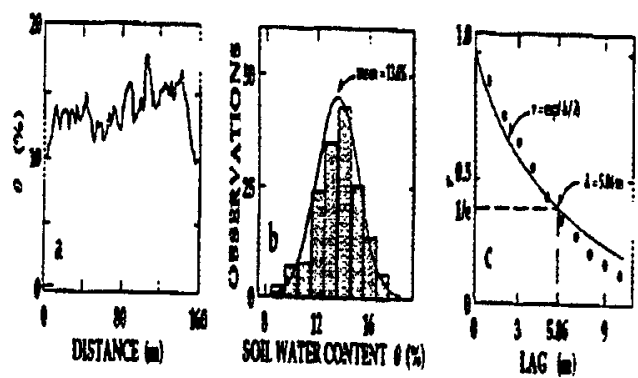

Figure 31 - a Soil water content measured at $1 \mathrm{~m}$ intervals within a $160 \mathrm{~m}$ long transect. b. Histogram of values in a. c. Autocorrelogram of the values in a.
The utility of using both of the above concepts in crop and soil science is great. Neither is a substitute for the other. The approximately normal frequency distribution of $\theta$ given in Figure $31 \mathrm{~b}$ does not quantify the variability of the soil water content as regards the spatial arrangement of $\theta$ but merely treats the values in terms of their magnitudes independent of their spatial position. The two concepts (frequency distribution and spatial variability) should not be confused. Using the first concept, it is possible to calculate the probability of an observation occurring within specified confidence intervals. This calculation, however, provides identical information for expected values for all locations. Different expected values for specific locations cannot be obtained. On the other hand, using the second concept, the autocorrelation function provides information about the separation distances within which observed values are related to each other. The spatial structure of a set of observations does not provide information about the frequency distribution of the observations. The fact that a set of observations manifests no spatial structure does not imply that the observations are normally distributed, and vice versa. The soil water content data in Figure 31a constitute a set of observations being normally distributed, yet those observations separated by less than $6 \mathrm{~m}$ are dependent on each other as expressed by $\lambda$ in Figure 3lc. The concept of randomness associated with the normal distribution should not lead to the conclusion that locations for field observations of soil water properties should be selected randomly.

Crosscorrelation: The concept of spatial autocorrelation is easily extended to two kinds of observations $\left(\mathrm{O}_{1}\right.$ and $\left.\mathrm{O}_{2}\right)$ to calculate the crosscorrelation coefficient $r_{C}$

$$
\begin{aligned}
& r_{C}(h)=\operatorname{cov}\left[O_{1}(x+h), O_{2}(x)\right] \\
& \left\{\operatorname{var}\left[O_{1}(x+h)\right] \operatorname{var}\left[O_{2}(x)\right]\right\}^{-1 / 2}
\end{aligned}
$$

The utility of spatial or temporal crosscorrelation should be obvious - it allows the investigator to consider the spacing and size of one set of observations with those of another. For example, at what distance should a tensiometer be placed in relation to a neutron meter access tube? Or, at what distance should a soil sample be taken in relation to the crown of a crop plant? 
Spectral and Cospectral analyses: Above, the interpretation of the correlation coefficients $\mathrm{r}$ and Ic were applicable to observations compared more or less in near vicinity to each other (i.e., for $h$ much, much less than the width of the field being sampled). An opportunity to discern repetitious irregularities or cyclic patterns in soil or plant communities across a field exists with spectral analysis that utilizes the function $\mathbf{r}(\mathrm{h})$, or with cospectral analysis that utilized the function $\mathrm{rc}(\mathrm{h})$. A spectral analysis identifies periodicities and can be calculated by

$$
S(f)=2 \int_{0}^{\infty} r(h) \cos (2 \pi f h) d h
$$

where $f$ is the frequency equal to $p^{-1}$ and $p$ is the spatial period. In a similar manner, $\mathrm{r}_{\mathrm{C}}(\mathrm{h})$ is used to partition the total covariance for two sets of observations across a field. A cospectral analysis is made by

$$
C o(f)=2 \int_{0}^{\infty} \overline{r_{c}}(h) \cos (2 \pi f h) d h
$$

where $\tilde{r}_{c}(h)=\frac{\left[r_{c}(h<0)+r_{c}(h>0)\right]}{2}$

Spectral and cospectral analyses are potentially powerful tools for managing and increasing our knowledge of land resources. With them, we can spatially link observations of different physical, chemical, and biological phenomena. We can identify the existence and persistence of cyclic patterns across the landscape. In some cases, the cyclic behavior of soil attributes may be of more or equal importance than the average behavior. From a spectral analysis, some insights may be gained relative to the distances over which a meaningful average should be calculated. And, with spectral analyses, it is possible to filter out trends across a field to examine local variations more closely, or vice versa. The following example illustrates the additional information gained from a spectral analysis of a set of solute observations taken from a soil profile by Gelhar et al. (1980). The soil was sampled at $30 \mathrm{~cm}$ intervals to a depth of $22 \mathrm{~m}$ (See Figure 32a). The spectrum S(0 [equation
(89)] shown in Figure $32 b$ has a peak at $f=0.37$ $\mathrm{m}^{-1}$, which indicates a period of $2.7 \mathrm{~m}$. Hence, the fluctuations of solute concentrations in Figure 31a are indicative of annual cycles of leaching associated with irrigation in the desert environment of New Mexico. Disregarding the spatial distribution of the concentration value leads only to a standard deviation of about 0.5 mg. $1^{-1}$ - a classical parameter that adds little to our understanding of the leaching process.
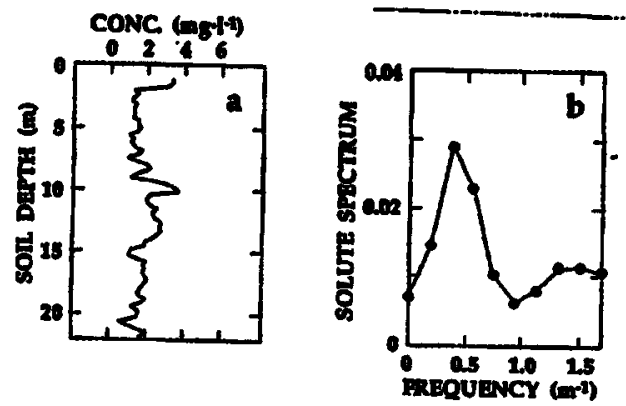

Figure 32 - a. Concentration distribution of solutes measured at $30 \mathrm{~cm}$ depth intervals. b. Spectral density function of the solute distribution of a.

State-Space Analysis: Thirty-seven years ago Kalman (1960) introduced the use of a linear estimation theory with stochastic regression coefficients to filter noisy electrical data in order to extract a clear signal or to predict ahead of the last observation. Kalman filtering is commonplace in electrical and mechanical engineering. Shumway \& Stoffer (1982) extended the concept of Kalman filtering to smooth and forecast relatively short and non stationary economic series observed in time. Using this state-space model, a series of observations can be smoothed, missing observations can be estimated, and values outside the domain of observation can be predicted. For the purpose of prediction one can calculate confidence intervals to demonstrate the reliability of the forecasting. Reliability of the prediction will depend on the adequacy of the available model and number of predictions outside the domain of observations. Morkoc et al. (1985) utilized the state-space model to analyze spatial variations of surface soil water content and soil surface temperature as a dynamic bivariate system. Following the suggestion of Shumway \& 
Stoffer (1982), Morkoc et al. described the variables of the observation model as

$$
\mathrm{Y}_{\mathrm{i}}=\mathrm{M}_{\mathrm{i}} \mathrm{Z}_{\mathrm{i}}+\mathrm{v}_{1} \quad \mathrm{i}=1,2,3,
$$

where $\mathrm{M}_{\mathrm{i}}$ is a known $\mathrm{q} \times \mathrm{p}$ observation matrix which expresses the pattern and converts the unobserved stochastic vector $Z_{1}$ into $q \times 1$ observed series $Y_{i}$, and $n_{i}$ is the observation noise or measurement error. Equation (13) written in matrix form for the bivariate system of Morkoc et al. is

$$
\left(\begin{array}{c}
W_{i}^{0} \\
T_{i}^{0}
\end{array}\right)=\left(\begin{array}{c}
W_{1} \\
T_{1}
\end{array}\right)+\left(\begin{array}{l}
v_{W_{i}} \\
v_{T_{1}}
\end{array}\right)
$$

where $W_{1}^{0}$ and $T_{1}^{0}$ are the ith soil water content and the ith soil surface temperature observations, respectively. Equation (92) indicates that an observation of either soil variable consists of two parts. The observational noise or measurement errors may be generated either by errors in measuring $W_{1}^{0}$ or $T_{i}^{0}$ or by ignoring other variables which affect either soil water content or soil surface temperature. For example, soil temperature is not only affected by incoming solar radiation but also by mineralogical composition, microtopography, texture, structure and color of the soil surface. Hence, any omitted variables such as texture or color enter into the state-space system as observational noise or measurement error $v_{1}$.

Values of soil water content and surface temperature were modeled as a first-order multivariate process of the form

$$
Z_{i}=\phi Z_{i-1}+\omega_{1}
$$

where $\phi$ is a $p \times p$ matrix of state-space coefficients. Many other functions of multivariate processes equally applicable to site-specific crop management await future investigation. The matrix form of the above equation is

$$
\left(\begin{array}{c}
W_{1} \\
T_{1}
\end{array}\right)=\left(\begin{array}{ll}
\phi_{11} & \phi_{12} \\
\phi_{21} & \phi_{22}
\end{array}\right)\left(\begin{array}{c}
W_{1-1} \\
T_{1-1}
\end{array}\right)+\left(\begin{array}{l}
v_{w_{1}} \\
v_{T_{1}}
\end{array}\right)
$$

Values of $\phi_{\mathrm{ij}}$ and the error terms of the above equation can be calculated using recursive procedures (Shumway \& Stoffer, 1982).

Details and the results of the state-space analysis of water content and temperature relations of a soil surface (without vegetation and having been non-uniformly sprinkler irrigated) are available (Morkoc et al., 1985). More directly relevant to the topic of this workshop is the application of equations similar to (91) and (93) to improve our understanding and management of biological processes as they occur in the field and to prioritize those soil attributes that contribute the most to sustainable agriculture.

\section{REFERENCES}

CLARK, I. Practical Geostatistics. Applied Science Publish, London. 1979.

DANCKWERTS P.V. Continuous flow systems. Chemical Engineering Science, v.2,p.1-13, 1953.

DAVIS, J. C. Statistics and Data Analysis in Geology. John Wiley \& Sons, Inc., New York. 1973.

GELHAR, L. W.; WIERENGA, P.J.; DUFFY, C.J.; REHFELDT, K. R.; SENN, R. B.; SIMONETT, M; YEH, T.C.; GUTJAHR, A L.; STRONG, W. R.; BUSTAMANTE, A Irrigation return flow studies at San Acacia. New Mexico: Monitoring modeling and variability. Technical Progress Report No. H-3, New Mexico Institute of Mining and Technology, Socorro. 1980.

IWATA, S.; TABUCHI, T.; WARKENTIN, B.P. Soil Water Interactions. M. Dekker, New York and Basel. 1988.

JACKSON, R.D. Water vapor diffusion in relatively dry soil 1. Soll Science Society of Am.erican Proceedings, v.28, p.172-176, 1964.

JOURNEL, AG.; HUIJBREGTS, C.H.J. Mining Geostatistics. Acad. Press. New York. 1978.

KALMAN, R.E. A new approaich to linear filtering and predicting problems. Trans. ASME of Basic Eng. 8:3545. 1960 .

KUTILEK M.; NIELSEN, D.R. Soil Hydrology. Catena Verlag, Cremlingen-Destedt, Germany. 1994.

MCLAREN AD. Temporal and vectorial reactions of nitrogen in soil: A review. Canadian Journal of Soil Science, v.50, p.97-109, 1970. 
MORKOC, F.; BIGGAR, J.W;; NIELSEN, D.R; ROLSTON, D.E. Analysis of soil water content and temperature using state-space approach. Soll Science Society of America Joumal, v.49, n.4, p.798-803, 1985.

RICHARDS L.A. Physical condition of water in soil. In: C.A. Black (Ed.): Methods of Soil Analysis, Part 1, Physical and Mineralogical Properties, Agronomy Monograph Series No. 9, ASA, Madison, p. 128-152. 1965.

SHUMWAY, R.H. Applied Statistical Time Series Analysis. Prentice-Hall, Englewood Cliffs, New Jersey, 1988.

SHUMWAY, R.H.; STOFFER, D.S. An approach to time series smoothing and forecasting using the EM algorithm. Jourmal of the Time Service Analisys, v.3:, p.253-264, 1982.
SRINILTA S.A; NIELSEN, D.R.; KIRKHAM, D. Steady flow of water through a two-layer soil. Water Resources Research, v.5, p.1053-1063, 1969.

TAKAGI, S. Analysis of the vertical downward flow of water through a two-layered soil. Soll Science, v.90, p.98-103, 1960.

WEBSTER, R; BURGESS, T.M. Spatial variation in soil and the role of kriging. Agricultural Water Management, v.6, p.111-122, 1983.

WILLIS W.O. Evaporation from layered soils in the presence of a water table. Soll SclenceSociety American Proceedings, v.24, p.239-242, 1960.

Recebido para publicaçăo em 25.04.97

Aceito para publicação em 15.05 .97 